\title{
UV-Vis-Induced Degradation of Phenol over Magnetic Photocatalysts Modified with Pt, Pd, Cu and Au Nanoparticles
}

\author{
Izabela Wysocka ${ }^{1}$, Ewa Kowalska ${ }^{2}$ (D), Konrad Trzciński ${ }^{1}$, Marcin Łapiński ${ }^{3}$, \\ Grzegorz Nowaczyk ${ }^{4}$ and Anna Zielińska-Jurek ${ }^{1, *}$ \\ 1 Faculty of Chemistry, Gdansk University of Technology, 80-233 Gdansk, Poland; iziawww@gmail.com (I.W.); \\ kontrzci@pg.edu.pl (K.T.) \\ 2 Institute for Catalysis (ICAT), Hokkaido University, Sapporo 001-0021, Japan; kowalska@cat.hokudai.ac.jp \\ 3 Faculty of Applied Physics and Mathematics, Gdansk University of Technology, 80-233 Gdansk, Poland; \\ marcin.lapinski@pg.edu.pl \\ 4 NanoBioMedical Center, Adam Mickiewicz University, 61-614 Poznan, Poland; nowag@amu.edu.pl \\ * Correspondence: annjurek@pg.edu.pl; Tel.: +48-58-347-23-52; Fax: +48-58-347-20-65
}

Received: 20 November 2017; Accepted: 1 January 2018; Published: 7 January 2018

\begin{abstract}
The combination of $\mathrm{TiO}_{2}$ photocatalyst and magnetic oxide nanoparticles enhances the separation and recoverable properties of nanosized $\mathrm{TiO}_{2}$ photocatalyst. Metal-modified (Me $=\mathrm{Pd}, \mathrm{Au}, \mathrm{Pt}, \mathrm{Cu}) \mathrm{TiO}_{2} / \mathrm{SiO}_{2} @ \mathrm{Fe}_{3} \mathrm{O}_{4}$ nanocomposites were prepared by an ultrasonic-assisted sol-gel method. All prepared samples were characterized by X-ray powder diffraction (XRD) analysis, Brunauer-Emmett-Teller (BET) method, X-ray photoelectron spectroscopy (XPS), scanning transmission electron microscopy (STEM), Mott-Schottky analysis and photoluminescence spectroscopy (PL). Phenol oxidation pathways of magnetic photocatalysts modified with $\mathrm{Pt}, \mathrm{Pd}$, $\mathrm{Cu}$ and $\mathrm{Au}$ nanoparticles proceeded by generation of reactive oxygen species, which oxidized phenol to benzoquinone, hydroquinone and catechol. Benzoquinone and maleic acid were products, which were determined in the hydroquinone oxidation pathway. The highest mineralization rate was observed for $\mathrm{Pd}-\mathrm{TiO}_{2} / \mathrm{SiO}_{2} @ \mathrm{Fe}_{3} \mathrm{O}_{4}$ and $\mathrm{Cu}-\mathrm{TiO}_{2} / \mathrm{SiO}_{2} @ \mathrm{Fe}_{3} \mathrm{O}_{4}$ photocatalysts, which produced the highest concentration of catechol during photocatalytic reaction. For Pt- $\mathrm{TiO}_{2} / \mathrm{SiO}_{2} @ \mathrm{Fe}_{3} \mathrm{O}_{4}$ nanocomposite, a lack of catechol after $60 \mathrm{~min}$ of irradiation resulted in low mineralization rate $\left(\mathrm{CO}_{2}\right.$ formation). It is proposed that the enhanced photocatalytic activity of palladium and copper-modified photocatalysts is related to an increase in the amount of adsorption sites and efficient charge carrier separation, whereas the keto-enol tautomeric equilibrium retards the rate of phenol photomineralization on $\mathrm{Au}-\mathrm{TiO}_{2} / \mathrm{SiO}_{2} @ \mathrm{Fe}_{3} \mathrm{O}_{4}$. The magnetization hysteresis loop indicated that the obtained hybrid photocatalyst showed magnetic properties and therefore could be easily separated after treatment process.
\end{abstract}

Keywords: heterogeneous photocatalysis; magnetic photocatalysts; modification of titanium(IV) oxide; mechanism of degradation; noble metal nanoparticles; phenol

\section{Introduction}

Degussa (Evonik) $\mathrm{TiO}_{2} \mathrm{P} 25$ consisting of a mixture of anatase $(\sim 78 \%)$, rutile $(\sim 14 \%)$ phases and a minor amount of amorphous phase $(\sim 8 \%)$ is a well-known commercial material frequently used to oxidize organic and inorganic compounds in air and water due to its strong oxidative ability and long-term photo-stability [1,2]. The photocatalytic activity of $\mathrm{TiO}_{2} \mathrm{P} 25$ is affected by light absorption, charge creation/recombination rate and surface activity. However, based on practicality, $\mathrm{TiO}_{2}$-based photocatalysis has some technical limitations that impede its commercialization. The first one is 
the separation and recovery of fine $\mathrm{TiO}_{2}$ particles after purification process. The sedimentation of photocatalyst is usually insufficient. Even when the photocatalyst flocculates, there is often some residue of $\mathrm{TiO}_{2}$ nanoparticles in the supernatant. In this regard, the combination of photocatalyst and magnetic particles is a suitable solution for the separation issue, allowing for a complete recovery of $\mathrm{TiO}_{2}$-based nanomaterial [3]. In recent years, the incorporation of magnetic particles into $\mathrm{TiO}_{2}$-based photocatalysts has attracted considerable attention. However, some shortcomings of magnetic photocatalysts have been also reported. For example, Beydoun et al. stated that direct contact between $\mathrm{TiO}_{2}$ and iron oxides (e.g., $\mathrm{Fe}_{3} \mathrm{O}_{4}, \mathrm{Fe}_{2} \mathrm{O}_{3}$ ) could decrease photocatalytic activity and reduce the magnetic properties due to photo-dissolution of iron phase induced by the $\mathrm{TiO}_{2}$ layer [4,5]. In this regard, the introduction of a silica intermediate passive layer could prevent an injection of charge carriers from titania shell into the iron oxide core and the subsequent leaching of iron ions into the solution [5]. The functionalization of the magnetic core consisting of magnetite [6], maghemite [7], hematite [8], $\mathrm{CoFe}_{2} \mathrm{O}_{4}$ [9], $\mathrm{ZnFe}_{2} \mathrm{O}_{4}$ spinel ferrites [10], $\mathrm{BaFe}_{12} \mathrm{O}_{19}$ hexagonal ferrites [9], bimetallic nanoparticles of Fe-Ni, Co-Fe, Mn-Zn, Ni-Cu-Zn [11,12] with $\mathrm{TiO}_{2}$ and intermediate $\mathrm{SiO}_{2}$ passive layer has recently been investigated.

However, there are very few reports in the literature regarding activation of magnetic photocatalysts under visible light. $\mathrm{TiO}_{2}$-based photocatalysts require an excitation wavelength that falls in the ultraviolet (UV) region. Since UV represents a small part (ca. 3-5\%) of the solar radiation, there is a need to design new photocatalysts with the ability to work under UV-visible light irradiation to provide better utilization of solar energy and to generate a greater number of photo-excited charge carriers. Magnetically-recoverable nitrogen-doped $\mathrm{TiO}_{2}$-based photocatalysts were studied for the degradation of phenol [13,14], p-nitrophenol [15], methyl orange [16], ibuprofen, benzochinone and carbamazepine [17]. Several studies have been reported using noble metals as the surface modifiers deposited on $\mathrm{TiO}_{2}$-based magnetic photocatalysts. Noble metals such as silver, gold, platinum, and palladium with a Fermi level lower than the electron affinity of $\mathrm{TiO}_{2}$ enhance electron-hole separation and possess the ability to absorb visible light due to localized surface plasmon resonance (LSPR) properties [18]. Magnetic photocatalysts modified with Ag, Pt, Ag-Pd or Au particles have been studied in the photocatalytic removal of chlorophenol [19], and mainly in the reaction of organic dye removal such as rhodamine $\mathrm{B}[20,21]$ and methylene blue [12,22]. Although the effect of $\mathrm{TiO}_{2} \mathrm{modified}$ with noble and semi-noble metal nanoparticles in photo-oxidation of chlorophenol [19] and dyes [20] for magnetic photocatalysts and chlorophenol [23,24], toluene [25-27], pesticides [28,29], carbonic acid [30,31], and dyes [32,33] for metal-modified $\mathrm{TiO}_{2}$ photocatalysts has been proved, the influence of the photocatalyst's structure on the photocatalytic activity and the mechanism of photocatalytic reaction still needs clarification. Reaction intermediates and product formation pathways depend on the physicochemical properties of the photocatalyst as well as experimental conditions, e.g., reaction environment, aeration, concentration and type of organic compounds, irradiation source and temperature [34-37]. Therefore, the direct comparison of experimental results with the literature on the effect of noble metal deposition on the photocatalytic activity is difficult.

In this regard, the aim of the present study is the determination of the phenol photo-oxidation mechanism in the presence of magnetically-separable noble metal-modified $(\mathrm{Me}=\mathrm{Pd}, \mathrm{Au}, \mathrm{Pt}, \mathrm{Cu})$ $\mathrm{Me}-\mathrm{TiO}_{2} / \mathrm{SiO}_{2} @ \mathrm{Fe}_{3} \mathrm{O}_{4}$ photocatalysts. The combination of $\mathrm{TiO}_{2}$ and magnetic oxide nanoparticles enhances the separation and recoverable properties of nanosized $\mathrm{TiO}_{2}$ photocatalyst under a magnetic field. Moreover, the metals deposited on $\mathrm{TiO}_{2}$ serve as a source of electron traps, which can increase the lifetime of separated electron-hole pairs, and thus enhance the efficiency and product selectivity for organic compound photodegradation [38]. However, the method of photocatalyst modification, i.e., surface or bulk, may also lead to the changes in reaction mechanism.

Phenol is an intermediate product aromatic hydrocarbon oxidation pathway; thus, it is commonly used as a model organic compound for advanced wastewater treatment reactions. $\mathrm{TiO}_{2}$ photocatalytic degradation of phenolic compounds has been intensively studied, and focus was put mainly on preparation and modification of new photocatalytic materials. The main phenol degradation 
intermediates are hydroquinone, benzoquinone, catechol, resorcinol, salicylic acid, 1,2,3-benzotriol, glycerol, muconic acid, maleic acid, oxalic acid and formaldehyde [39], which are generated under aerobic conditions. Su et al. [37] proposed a mechanism of phenol degradation over Au/Pd bimetallic particle-modified $\mathrm{TiO}_{2}$ as a result of nonselective hydroxyl radical attack, leading to the generation of p-benzoquinone and hydroquinone. For commercial titanium(IV) oxide, P25, it was observed that only hydroquinone appeared in substantial amounts. Catechol presence was also detected; however, the concentration was negligible. It was found that, during phenol photodegradation, the hydroquinone pathway was a limiting step. Zhang et al. [40] found that catechol and hydroquinone were the main products generated immediately during phenol photocatalytic oxidation. The next step was further hydroxylation of the aromatic ring leading to the occurrence of a trisubstituted compound such as pyrogallol. They stated that the final step of phenol oxidation should have been organic acids; however, their presence was not confirmed. In some studies [41], it has been proposed that oligomerization or polimerization reactions occurred, yielding non-oxidizable compounds.

In the present study, to provide insight into the mechanism of phenol degradation, the determination of oxidative species participating in the degradation mechanism has been investigated by reference experiments in the presence of scavengers $\left(\mathrm{h}_{\mathrm{vb}}{ }^{+}, \mathrm{e}_{\mathrm{cb}}{ }^{-}\right.$and free radicals). The correlation between surface properties of magnetic nanocomposites modified with $\mathrm{Au}, \mathrm{Pd}, \mathrm{Pt}$ or $\mathrm{Cu}$ and photocatalytic activities has been studied. The effect of the noble metal loadings on phenol oxidation pathways via various intermediates, and finally its mineralization, measured as total organic carbon (TOC) reduction, has been investigated for the first time.

\section{Results}

\subsection{Characterization of Nanocomposites}

X-ray diffraction (XRD) patterns of $\mathrm{TiO}_{2} / \mathrm{SiO}_{2} @ \mathrm{Fe}_{3} \mathrm{O}_{4}$ samples modified with nanoparticles of $\mathrm{Cu}, \mathrm{Pt}, \mathrm{Pd}$ and $\mathrm{Au}$ are shown in Figure 1. All prepared samples revealed high crystallinity of cubic spinel $\mathrm{Fe}_{3} \mathrm{O}_{4}$, anatase and rutile phases.

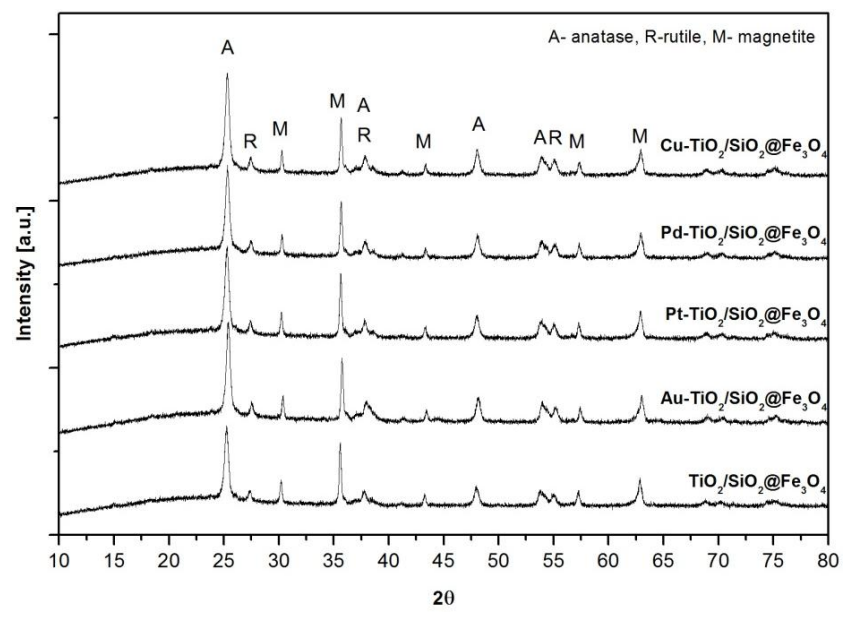

Figure 1. X-ray diffraction (XRD) patterns of $\mathrm{Me}-\mathrm{TiO}_{2} / \mathrm{SiO}_{2} @ \mathrm{Fe}_{3} \mathrm{O}_{4}$ nanocomposites.

The estimated values of phase content and crystallite sizes are presented in Table 1 . The average primary size of anatase crystals was about $20 \pm 0.5 \mathrm{~nm}$, whereas, for the rutile phase, it was $30 \pm 1 \mathrm{~nm}$. Anatase phase content estimated according to the Rietveld method fluctuated from $57 \pm 0.5$ to $64 \pm 3 \mathrm{wt} \%$, whereas, for rutile, it was from $6.5 \pm 0.2$ to $8 \pm 1.4 \mathrm{wt} \%$. The diffraction peaks at $30^{\circ}$, $35.6^{\circ}, 43.3^{\circ}, 57.3^{\circ}, 62.9^{\circ}$ correspond to [220], [311], [400], [541] and [440] planes of cubic inverse spinel $\mathrm{Fe}_{3} \mathrm{O}_{4}$, respectively $[42,43]$. The average size of commercial magnetite crystallites estimated using the Scherrer equation for the main peak of magnetite [311] was about $44 \pm 1 \mathrm{~nm}$. Moreover, the 
broad diffraction peak at $2 \theta=15-25^{\circ}$ corresponded to an amorphous silica layer in the nanocomposite structure [44,45]. For $\mathrm{Au}-\mathrm{TiO}_{2} / \mathrm{SiO}_{2} @ \mathrm{Fe}_{3} \mathrm{O}_{4}$ nanocomposite, the presence of gold nanoparticles (NPs) with diameter of about $21 \pm 1 \mathrm{~nm}$ was confirmed by diffraction peaks at $64.8^{\circ}$ and $77.8^{\circ} 2 \theta$ for $\mathrm{Au}$ [220] and [311]. However, other metal nanoparticles were hardly detected on the surface of $\mathrm{TiO}_{2}$ indicating either a small amount of deposited metal or a small size of metallic NPs.

Table 1. Characteristic of physicochemical properties of $\mathrm{TiO}_{2} / \mathrm{SiO}_{2} @ \mathrm{Fe}_{3} \mathrm{O}_{4}$ and $\mathrm{Me}-\mathrm{TiO}_{2} / \mathrm{SiO}_{2} @ \mathrm{Fe}_{3} \mathrm{O}_{4}$ photocatalysts.

\begin{tabular}{|c|c|c|c|c|c|c|c|}
\hline \multirow{4}{*}{ Photocatalyst } & \multicolumn{6}{|c|}{ Crystalline Size } & \multirow{4}{*}{$\begin{array}{l}\text { Magnetization } \\
\left(\mathrm{emu}^{\left.-\mathrm{g}^{-1}\right)}\right.\end{array}$} \\
\hline & \multicolumn{4}{|c|}{$\mathrm{TiO}_{2}$} & \multirow{2}{*}{\multicolumn{2}{|c|}{ Magnetite }} & \\
\hline & \multicolumn{2}{|c|}{ Anatase } & \multicolumn{2}{|c|}{ Rutile } & & & \\
\hline & Size $(\mathrm{nm})$ & $\begin{array}{c}\text { Phase } \\
\text { Content wt \% }\end{array}$ & Size (nm) & $\begin{array}{c}\text { Phase } \\
\text { Content wt \% }\end{array}$ & Size $(\mathrm{nm})$ & $\begin{array}{c}\text { Phase } \\
\text { Content wt \% }\end{array}$ & \\
\hline $\mathrm{TiO}_{2} / \mathrm{SiO}_{2} @ \mathrm{Fe}_{3} \mathrm{O}_{4}$ & 20 & $57 \pm 0.5$ & 30 & $8 \pm 1$ & 44.5 & $34 \pm 1$ & 11 \\
\hline $\mathrm{Pt}-\mathrm{TiO}_{2} / \mathrm{SiO}_{2} @ \mathrm{Fe}_{3} \mathrm{O}_{4}$ & 19.5 & $63 \pm 2.5$ & 28 & $6.5 \pm 0.2$ & 44 & $29 \pm 2$ & 12 \\
\hline $\mathrm{Pd}-\mathrm{TiO}_{2} / \mathrm{SiO}_{2} @ \mathrm{Fe}_{3} \mathrm{O}_{4}$ & 19 & $64 \pm 3$ & 31 & $8 \pm 1.4$ & 43 & $29 \pm 2.5$ & 9.5 \\
\hline $\mathrm{Cu}-\mathrm{TiO}_{2} / \mathrm{SiO}_{2} @ \mathrm{Fe}_{3} \mathrm{O}_{4}$ & 20 & $61 \pm 3$ & 30 & $7.5 \pm 0.5$ & 44 & $30 \pm 3$ & 10 \\
\hline $\mathrm{Au}-\mathrm{TiO}_{2} / \mathrm{SiO}_{2} @ \mathrm{Fe}_{3} \mathrm{O}_{4}$ & 20 & $60 \pm 1$ & 31 & $7 \pm 0.8$ & 42 & $32 \pm 2$ & 11 \\
\hline
\end{tabular}

The magnetic properties of $\mathrm{Me}-\mathrm{TiO}_{2} / \mathrm{SiO}_{2} @ \mathrm{Fe}_{3} \mathrm{O}_{4}$ nanocomposites were measured at room temperature $(293 \mathrm{~K})$, and obtained results are presented in Figure 2 and Table 1.
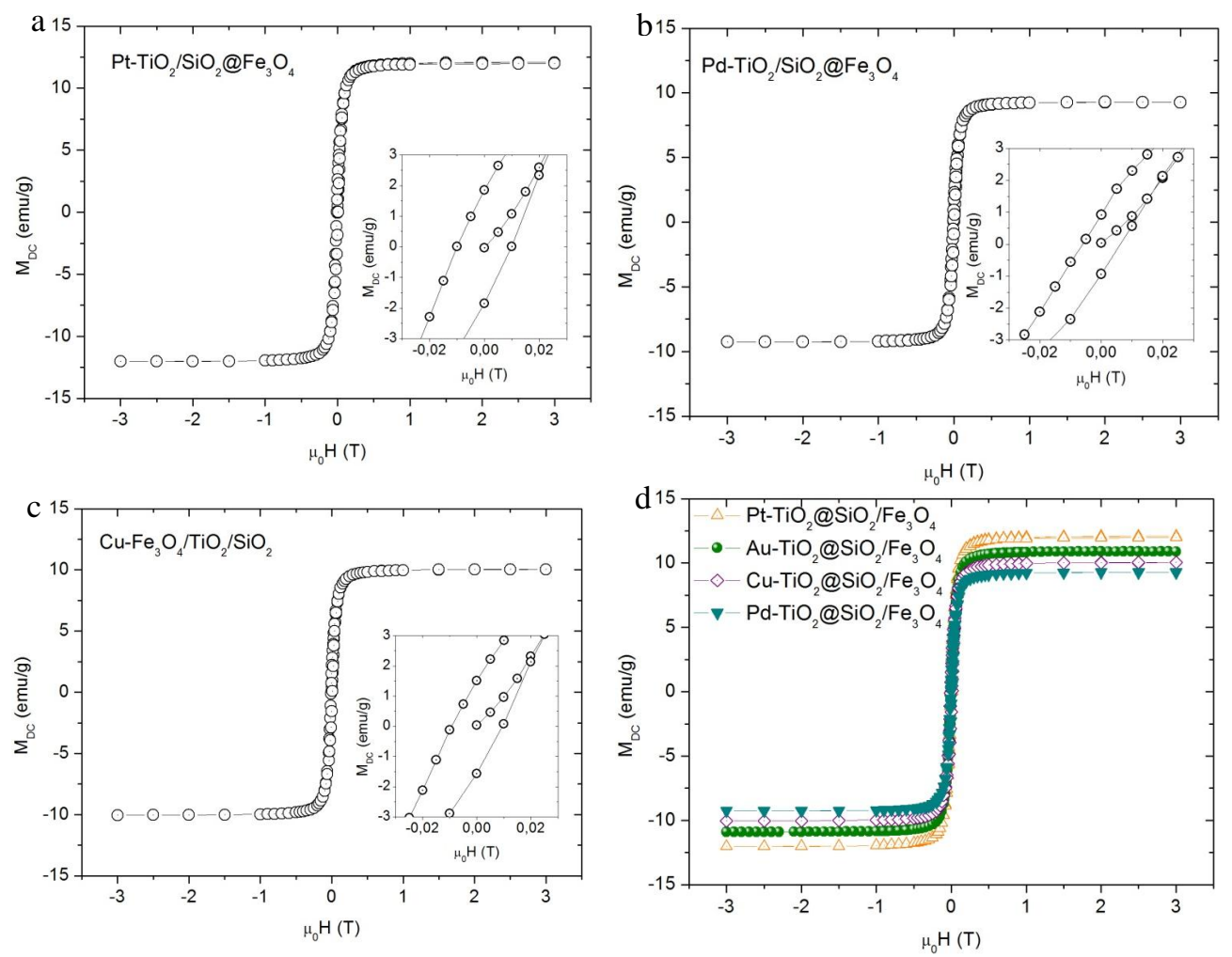

Figure 2. Magnetic hysteresis for (a) $\mathrm{Pt}-\mathrm{TiO}_{2} / \mathrm{SiO}_{2} @ \mathrm{Fe}_{3} \mathrm{O}_{4} ;$ (b) $\mathrm{Pd}-\mathrm{TiO}_{2} / \mathrm{SiO}_{2} @ \mathrm{Fe}_{3} \mathrm{O}_{4}$; (c) $\mathrm{Cu}-\mathrm{TiO}_{2} / \mathrm{SiO}_{2} @ \mathrm{Fe}_{3} \mathrm{O}_{4}$; (d) all obtained $\mathrm{Me}-\mathrm{TiO}_{2} / \mathrm{SiO}_{2} @ \mathrm{Fe}_{3} \mathrm{O}_{4}$ nanocomposites and magnification at hysteresis loop start point.

For all obtained photocatalysts, the magnetic saturation reached ca. $10-12 \mathrm{emu} \cdot \mathrm{g}^{-1}$ and did not depend on the amount of ferrite fraction in the nanocomposite and noble metal presence at the surface of $\mathrm{TiO}_{2}$.

The surface composition of $\mathrm{Me}-\mathrm{TiO}_{2} / \mathrm{SiO}_{2} @ \mathrm{Fe}_{3} \mathrm{O}_{4}$ nanocomposites and oxidation states of $\mathrm{C} 1 \mathrm{~s}$, Ti 2p and Fe 2p were determined by X-ray photoelectron spectroscopy (XPS) analysis, and the obtained data are presented in Table 2. 
Table 2. X-ray photoelectron spectroscopy (XPS) analysis of oxygen, titanium, carbon and metal for $\mathrm{Me}-\mathrm{TiO}_{2} / \mathrm{SiO}_{2} @ \mathrm{Fe}_{3} \mathrm{O}_{4}$ photocatalysts, and fraction of oxidation states from deconvolution of XPS peaks of Ti $2 \mathrm{p}$ and $\mathrm{C} 1 \mathrm{~s}$.

\begin{tabular}{|c|c|c|c|c|c|c|c|c|c|c|c|c|}
\hline \multirow{2}{*}{ Photocatalyst } & \multicolumn{5}{|c|}{ Content (at.\%) } & \multicolumn{2}{|c|}{$\operatorname{Ti} 2 \mathrm{p}_{3 / 2}(\%)$} & \multicolumn{5}{|c|}{ C 1s (\%) } \\
\hline & Ti 2p & O 1s & Si 2p & C 1s & Metal & $\mathrm{Ti}^{4+}$ & $\mathrm{Ti}^{3+}$ & C-C & C-O & $\mathrm{C}=\mathrm{C}$ & $\mathrm{C}=\mathrm{O}$ & $\mathrm{COOH}$ \\
\hline $\mathrm{TiO}_{2} / \mathrm{SiO}_{2} @ \mathrm{Fe}_{3} \mathrm{O}_{4}$ & 8.7 & 60.0 & 20.4 & 10.9 & 0 & 97.0 & 3.0 & 34.0 & 24.5 & 12.8 & 18.1 & 10.5 \\
\hline $\mathrm{Pd}-\mathrm{TiO}_{2} / \mathrm{SiO}_{2} @ \mathrm{Fe}_{3} \mathrm{O}_{4}$ & 8.3 & 59.4 & 20.5 & 11.6 & 0.2 & 96.0 & 4.0 & 33.9 & 21.5 & 22.0 & 11.5 & 9.0 \\
\hline $\mathrm{Cu}-\mathrm{TiO}_{2} / \mathrm{SiO}_{2} @ \mathrm{Fe}_{3} \mathrm{O}_{4}$ & 6.7 & 56.5 & 22.6 & 13.4 & 0.8 & 96.0 & 4.0 & 43.1 & 41.2 & 8.4 & 2.9 & 4.4 \\
\hline $\mathrm{Au}-\mathrm{TiO}_{2} / \mathrm{SiO}_{2} @ \mathrm{Fe}_{3} \mathrm{O}_{4}$ & 9.8 & 57.6 & 19.1 & 13.3 & 0.2 & 97.0 & 3.0 & 31.5 & 43.4 & 18.8 & 3.0 & 3.3 \\
\hline $\mathrm{Pt}-\mathrm{TiO}_{2} / \mathrm{SiO}_{2} @ \mathrm{Fe}_{3} \mathrm{O}_{4}$ & 8.5 & 59.6 & 22.3 & 9.5 & 0.1 & 97.0 & 3.0 & 41.1 & 35.5 & 7.4 & 15.4 & 0.6 \\
\hline
\end{tabular}

The main fraction of each nanocomposite was oxygen, as a component of $\mathrm{TiO}_{2}, \mathrm{SiO}_{2}$ and $\mathrm{Fe}_{3} \mathrm{O}_{4}$. The content of oxygen varied from 53.5 to 59.6 at.\%. In all $\mathrm{Me}-\mathrm{TiO}_{2} / \mathrm{SiO}_{2} @ \mathrm{Fe}_{3} \mathrm{O}_{4}$ nanocomposites, the peak at binding energy (BE) $289-284 \mathrm{eV}$ attributed to $\mathrm{Si} 2 \mathrm{p}$ was observed. The peak attributed to C $1 \mathrm{~s}$ was observed at around $284-288 \mathrm{eV}$. The $\mathrm{C} 1 \mathrm{~s}$ region could be deconvoluted for five peaks. It was found that carbon appeared as the $\mathrm{COOH}(\mathrm{BE} \sim 288.8 \mathrm{eV}), \mathrm{C}=\mathrm{O}(\mathrm{BE} \sim 287.3 \mathrm{eV}), \mathrm{C}-\mathrm{OH}(\mathrm{BE} 285.3 \mathrm{eV})$ and $\mathrm{C}-\mathrm{C}$ (aromatic and aliphatic) bonds (BE 283.8 eV and BE $284.3 \mathrm{eV}$, respectively). Carbon content varied from 9.5 to 13.4 at.\% and was observed in the surface layer for all obtained photocatalysts, even for pure $\mathrm{TiO}_{2}$ : see Table 2. Carbon content originated from the organic precursor of silica (TEOS) and the reaction environment. The correlation between carbon content and UV-visible irradiation-induced activity was not observed. Moreover, the band gaps for $\mathrm{TiO}_{2}$ and noble metal modified magnetic photocatalysts were similar and equaled $3.1 \mathrm{eV}$. Based on energy-dispersive X-ray spectroscopy (EDS) analysis, the carbon content was about $2 \mathrm{wt} \%$ in all obtained photocatalysts.

The Ti $2 \mathrm{p}$ spectrum could be deconvoluted into two components at 458.6 and $458.1 \mathrm{eV}$ binding energies and could be identified with $\mathrm{TiO}_{2}$ and $\mathrm{Ti}_{2} \mathrm{O}_{3} / \mathrm{Ti}^{3+}$ (in lattice, i.e., "self-doped titania"), respectively [46]. The presence of $\mathrm{Ti}_{2} \mathrm{O}_{3}$ is not expected in well-crystallized titania P25, where even thermal treatment did not cause meaningful phase transition, e.g., an increase in rutile content from 14.4 to 18.8 was observed after $2 \mathrm{~h}$ calcination of $\mathrm{P} 25$ sample at $500{ }^{\circ} \mathrm{C}$ [47]. Intensities of $\mathrm{Ti}^{4+}$ and $\mathrm{Ti}^{3+}$ components showed that $\mathrm{Ti}^{4+}$ was the dominant surface state $(96-97 \%)$ for all obtained photocatalysts. The presence of all deposited metals was confirmed by XPS analysis, but their presence did not change significantly the surface composition of photocatalyst.

Moreover, the presence of platinum and silver was confirmed by (scanning electron microscopy/energy-dispersive X-ray spectroscopy (SEM/EDS) as is shown in Table 3. It must be pointed that, although metals were detected in all samples by SEM/EDS, their amounts were higher compared to XPS and slightly lower than used for deposition.

Table 3. XPS and scanning electron microscopy/ energy-dispersive X-ray spectroscopy (SEM/EDS) results of the noble metal content in the magnetic photocatalysts.

\begin{tabular}{cccc}
\hline & \multicolumn{3}{c}{ Amount of Metal } \\
\cline { 2 - 4 } Photocatalyst & Used for Deposition (mol \%) & \multicolumn{2}{c}{ Deposited } \\
\cline { 3 - 4 } & & EDS (wt \%) & XPS (at.\%) \\
\hline $\mathrm{TiO}_{2} / \mathrm{SiO}_{2} @ \mathrm{Fe}_{3} \mathrm{O}_{4}$ & 0.5 & 0 & 0 \\
$\mathrm{Pd}-\mathrm{TiO}_{2} / \mathrm{SiO}_{2} @ \mathrm{Fe}_{3} \mathrm{O}_{4}$ & 0.5 & 0.5 & 0.2 \\
$\mathrm{Cu}-\mathrm{TiO}_{2} / \mathrm{SiO}_{2} @ \mathrm{Fe}_{3} \mathrm{O}_{4}$ & 0.5 & 0.79 & 0.8 \\
$\mathrm{Au}-\mathrm{TiO}_{2} / \mathrm{SiO}_{2} @ \mathrm{Fe}_{3} \mathrm{O}_{4}$ & 0.5 & 0.58 & 0.2 \\
$\mathrm{Pt}-\mathrm{TiO}_{2} / \mathrm{SiO}_{2} @ \mathrm{Fe}_{3} \mathrm{O}_{4}$ & & 0.1 \\
\hline
\end{tabular}

Figure 3a-c shows dark-field scanning transmission microscopy (DF-STEM) images of the prepared $\mathrm{Pd}-\mathrm{TiO}_{2} / \mathrm{SiO}_{2} @ \mathrm{Fe}_{3} \mathrm{O}_{4}, \mathrm{Cu}-\mathrm{TiO}_{2} / \mathrm{SiO}_{2} @ \mathrm{Fe}_{3} \mathrm{O}_{4}$ and $\mathrm{Pt}-\mathrm{TiO}_{2} / \mathrm{SiO}_{2} @ \mathrm{Fe}_{3} \mathrm{O}_{4}$ photocatalysts. $\mathrm{Pd}-\mathrm{TiO}_{2} / \mathrm{SiO}_{2} @ \mathrm{Fe}_{3} \mathrm{O}_{4}$ nanocomposite had small palladium nanoparticles with a diameter of about 
1-2 nm deposited on titania surface, whereas $\mathrm{Cu}-\mathrm{TiO}_{2} / \mathrm{SiO}_{2} @ \mathrm{Fe}_{3} \mathrm{O}_{4}$ contained copper particles with a diameter of about $10-12 \mathrm{~nm}$.
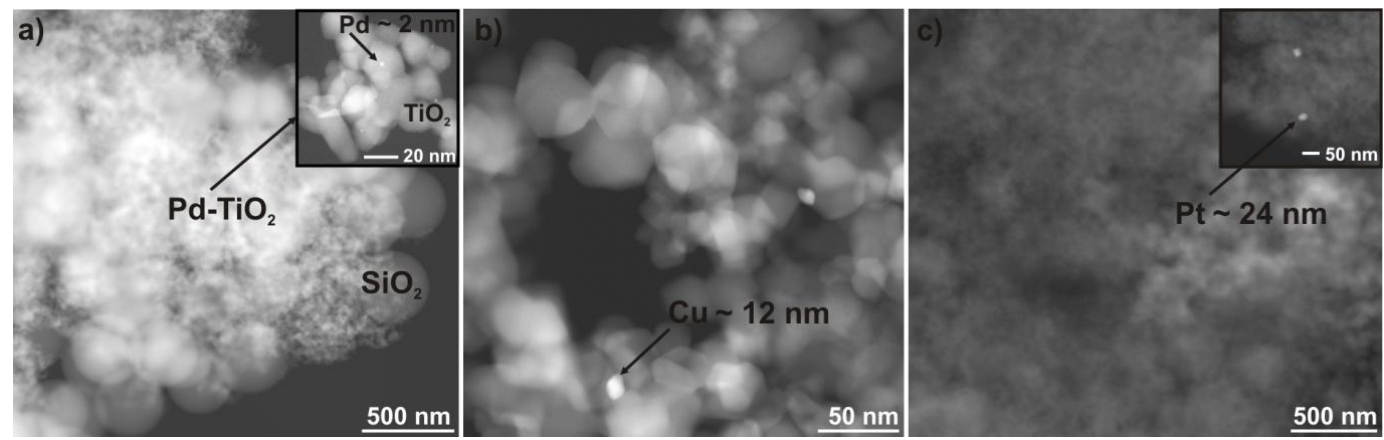

Figure 3. Dark-field scanning transmission (DF-STEM) microscopy images for (a) $\mathrm{Pd}-\mathrm{TiO}_{2} / \mathrm{SiO}_{2} @ \mathrm{Fe}_{3} \mathrm{O}_{4}$; (b) $\mathrm{Cu}-\mathrm{TiO}_{2} / \mathrm{SiO}_{2} @ \mathrm{Fe}_{3} \mathrm{O}_{4}$ and (c) $\mathrm{Pt}-\mathrm{TiO}_{2} / \mathrm{SiO}_{2} @ \mathrm{Fe}_{3} \mathrm{O}_{4}$ nanocomposites. Inserts for $(\mathbf{a}, \mathbf{c})$ : magnification of metal nanoparticles deposited on $\mathrm{TiO}_{2}$.

Sample $\mathrm{Pt}-\mathrm{TiO}_{2} / \mathrm{SiO}_{2} @ \mathrm{Fe}_{3} \mathrm{O}_{4}$ had a Pt particle size in the range from 20 to $24 \mathrm{~nm}$ deposited on the titania surface. The size of Au nanoparticles of ca. $21 \mathrm{~nm}$ determined from XRD patterns was in good agreement with the size obtained from the STEM analysis $(24 \mathrm{~nm})$. It is well known that the efficiency of the photocatalytic process depends strongly on the particle size of metal deposits and titania physicochemical properties. It was reported that small and monodisperse silver nanoparticles below $10 \mathrm{~nm}$ exhibited the highest photocatalytic and antimicrobial activity [48,49]. However, for gold nanoparticles deposited on titania, an increase in gold NP size resulted in the enhancement of photocatalytic activity, probably due to the ability of the photoabsorption of more photons by larger and rod-like gold nanoparticles of broad plasmonic absorption band $[50,51]$. On the contrary, a considerable increase of photocatalytic activity was observed for small platinum and palladium NPs $(2-3 \mathrm{~nm})$ deposited on $\mathrm{TiO}_{2}$ [52]. Therefore, it is assumed that the highest photocatalytic activity should reveal magnetic $\mathrm{TiO}_{2}$-based photocatalyst surfaces modified by fine palladium nanoparticles.

Mott-Schottky analysis was used to determine the location of flat band energy $\left(E_{\mathrm{fb}}\right)$ by measuring the space charge region capacitance $\left(C_{\mathrm{sc}}\right)$ at electrode/electrolyte interface. Exemplary Mott-Schottky plots of $\mathrm{Pt} / \mathrm{TiO}_{2}$ electrode are presented in Figure 4a. The capacitance of the space charge region was calculated using three different frequencies. As can be seen, different values of $E_{\mathrm{fb}}$ can be interpolated. The frequency dispersion is observed due to the electrode porosity. An exemplary impedance spectrum with appropriate fitting and used equivalent circuit (EQC) is presented in Figure $4 \mathrm{~b}$. The proposed EQC consists of the lowest possible amount of elements.
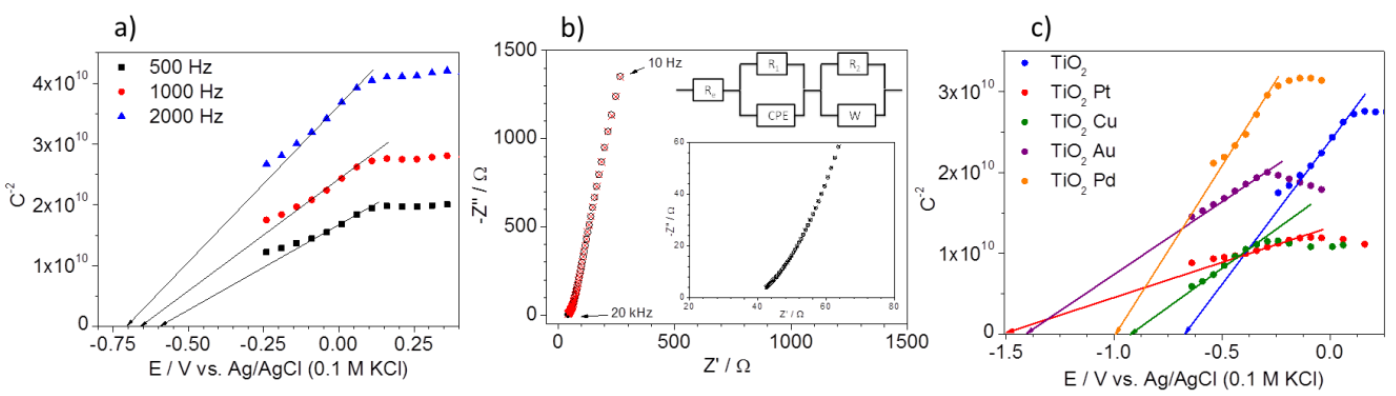

Figure 4. (a) Mott-Schottky plot of unmodified photocatalyst (space charge region capacitance calculated for 3 different frequencies); (b) Exemplary impedance spectrum and fitted data of unmodified $\mathrm{TiO}_{2}$ (recorded at $0 \mathrm{~V}$ vs. $\mathrm{Ag} / \mathrm{AgCl}(0.1 \mathrm{M} \mathrm{KCl})$. Insert: equivalent circuit used to model spectrum, and (c) comparison of Mott-Schottky plots recorded for $\mathrm{TiO}_{2}, \mathrm{Cu}-\mathrm{TiO}_{2}, \mathrm{Pd}-\mathrm{TiO}_{2}, \mathrm{Au}-\mathrm{TiO}_{2}$, and $\mathrm{Pt}-\mathrm{TiO} \mathrm{O}_{2}$ (capacitances calculated for $1000 \mathrm{~Hz}$ ). 
The capacitance of the semiconductor/electrolyte interphase is fitted using constant phase element (CPE). The diffusional impedance "W" is related to the ionic transport inside the pores of deposited $\mathrm{TiO}_{2}$ to the blocking electrode (Pt). The comparison of Mott-Schottky analyses for un-modified and metal-modified $\mathrm{TiO}_{2}$ nanocomposites is presented in Figure 4c. The Mott-Schottky plots showed that $\mathrm{TiO}_{2}$ acts as an n-type (negative slope) semiconductor in all prepared photocatalysts. The flat band potential of $\mathrm{TiO}_{2}$ nanocomposite was estimated at $-0.69 \mathrm{~V}$ vs. $\mathrm{Ag} / \mathrm{AgCl}(0.1 \mathrm{M} \mathrm{KCl})$ and it is in good agreement with our previous results and literature data [53]. The flat band potentials were -0.925 , $-1.0,-1.405$ and $-1.5 \mathrm{~V}$ for $\mathrm{Cu}, \mathrm{Pd}, \mathrm{Au}$ and $\mathrm{Pt}$ modified nanocomposites, respectively. For all obtained photocatalysts, a significant cathodic shift of the flat band gap potential was observed. Tanabe and Ozaki [54] reported that photocatalytic properties of $\mathrm{Me}-\mathrm{TiO}_{2}$ photocatalysts depended on the work function of the used metal. Therefore, it can be concluded that the differences of work functions of $\mathrm{Cu}$, $\mathrm{Pd}, \mathrm{Au}$, and $\mathrm{Pt}$ may also affect the location of flat band potential of modified $\mathrm{TiO}_{2}$. Thus, the presence of metal nanoparticles on the surface of titania should enhance the ability of $\mathrm{TiO}_{2}$ to oxidize adsorbed species due to efficient electron trapping [55]. The Mott-Schottky plots also demonstrate the difference in the slopes of the curves of $\mathrm{TiO}_{2}$ and metal-modified $\mathrm{TiO}_{2}$ nanocomposites. There was a significant decrease in the slope of copper-modified $\mathrm{TiO}_{2}$ compared to that of $\mathrm{TiO}_{2}$, indicating an enhanced charge carrier density and faster charge transfer for $\mathrm{Cu}$-modified $\mathrm{TiO}_{2}$, which should contribute to higher photocatalytic activity.

\subsection{Phenol Photocatalytic Degradation}

The photocatalytic activity of the as-prepared nanocomposites was studied by examining the reaction of phenol degradation. No phenol was degraded in the absence of illumination, indicating that there was no dark reaction at the surface of $\mathrm{Me}-\mathrm{TiO}_{2} / \mathrm{SiO}_{2} @ \mathrm{Fe}_{3} \mathrm{O}_{4}$ nanocomposites.

Efficiency of phenol photodegration and total organic carbon (TOC) reduction under ultraviolet-visible (UV-vis) light in the presence of titanium(IV) oxide magnetic nanocomposites modified with platinum, palladium, copper or gold nanoparticles are presented in Figure 5a,b, respectively.
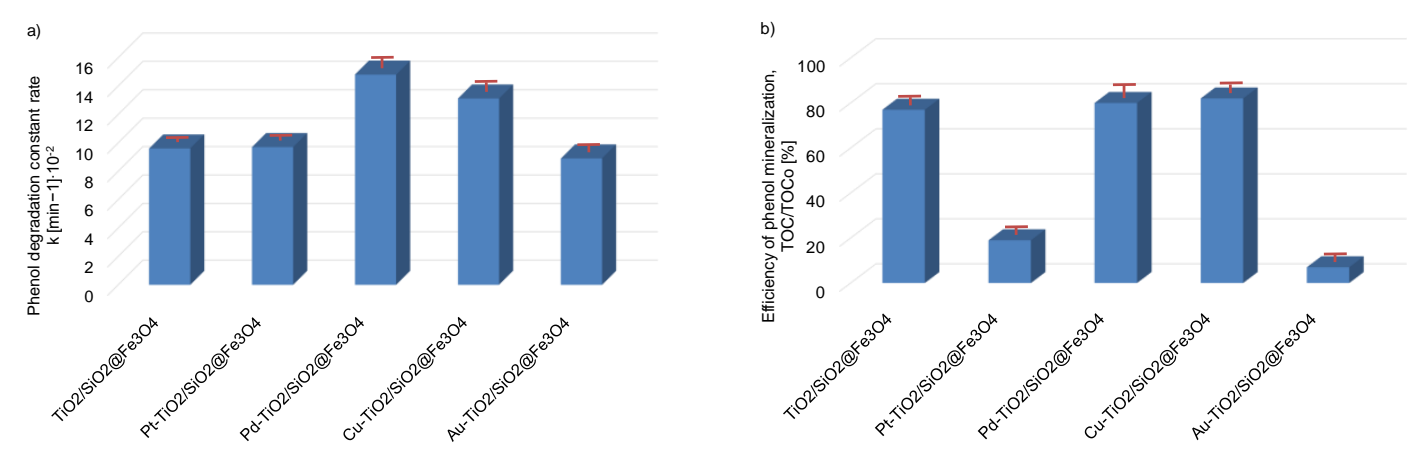

Figure 5. Photodegradation of phenol (a) and total organic carbon (TOC) reduction (b) under ultraviolet-visible (UV-Vis) light the presence of $\mathrm{Pt}-\mathrm{TiO}_{2} / \mathrm{SiO}_{2} @ \mathrm{Fe}_{3} \mathrm{O}_{4}, \mathrm{Pd}-\mathrm{TiO}_{2} / \mathrm{SiO}_{2} @ \mathrm{Fe}_{3} \mathrm{O}_{4}$, $\mathrm{Cu}-\mathrm{TiO}_{2} / \mathrm{SiO}_{2} @ \mathrm{Fe}_{3} \mathrm{O}_{4}$ and $\mathrm{Au}-\mathrm{TiO}_{2} / \mathrm{SiO}_{2} @ \mathrm{Fe}_{3} \mathrm{O}_{4}$ nanocomposites. Experimental conditions: phenol initial concentration Co. $=0.2 \times 10^{-3} \mathrm{M}$, content of photocatalyst $2 \mathrm{~g} \cdot \mathrm{dm}^{-3}, 300 \mathrm{~W}$ xenon lamp.

The apparent first-order constant rate of phenol photodegradation increased from $8.9 \times 10^{-2}$ $\pm 0.08 \mathrm{~min}^{-1}$ for $\mathrm{TiO}_{2} / \mathrm{SiO}_{2} @ \mathrm{Fe}_{3} \mathrm{O}_{4}$ and $\mathrm{Au}-\mathrm{TiO}_{2} / \mathrm{SiO}_{2} @ \mathrm{Fe}_{3} \mathrm{O}_{4}$ to $14.8 \times 10^{-2} \pm 0.27 \mathrm{~min}^{-1}$ for $\mathrm{Pd}-\mathrm{TiO}_{2} / \mathrm{SiO}_{2} @ \mathrm{Fe}_{3} \mathrm{O}_{4}$. The highest photo-oxidatation rate of phenol was observed for $\mathrm{Pd}-\mathrm{TiO}_{2} / \mathrm{SiO}_{2} @ \mathrm{Fe}_{3} \mathrm{O}_{4}$ and $\mathrm{Cu}-\mathrm{TiO}_{2} / \mathrm{SiO}_{2} @ \mathrm{Fe}_{3} \mathrm{O}_{4}$ photocatalysts. The 20-min irradiation by UV-vis light of $\mathrm{Cu}-\mathrm{TiO}_{2} / \mathrm{SiO}_{2} @ \mathrm{Fe}_{3} \mathrm{O}_{4}$ and $\mathrm{Pd}-\mathrm{TiO}_{2} / \mathrm{SiO}_{2} @ \mathrm{Fe}_{3} \mathrm{O}_{4}$ resulted in $76 \%$ and $83 \%$ phenol degradation, respectively. The removal rates of $\mathrm{TOC}$ for $\mathrm{Cu}-\mathrm{TiO}_{2} / \mathrm{SiO}_{2} @ \mathrm{Fe}_{3} \mathrm{O}_{4}$ and $\mathrm{Pd}-\mathrm{TiO}_{2} / \mathrm{SiO}_{2} @ \mathrm{Fe}_{3} \mathrm{O}_{4}$ were much higher compared to that for $\mathrm{Au}-\mathrm{TiO}_{2} / \mathrm{SiO}_{2} @ \mathrm{Fe}_{3} \mathrm{O}_{4}$ and $\mathrm{Pt}-\mathrm{TiO}_{2} / \mathrm{SiO}_{2} @ \mathrm{Fe}_{3} \mathrm{O}_{4}$ photocatalysts and quite similar to their efficiency of phenol degradation. For the most active $\mathrm{Cu}-\mathrm{TiO}_{2} / \mathrm{SiO}_{2} @ \mathrm{Fe}_{3} \mathrm{O}_{4}$ and $\mathrm{Pd}-\mathrm{TiO}_{2} / \mathrm{SiO}_{2} @ \mathrm{Fe}_{3} \mathrm{O}_{4}$ photocatalysts, 
the mineralization of phenol, measured as TOC reduction, was about $80 \pm 3 \%$ and decreased to $19 \pm 1 \%$ and $7 \pm 1 \%$ for $\mathrm{Pt}-\mathrm{TiO}_{2} / \mathrm{SiO}_{2} @ \mathrm{Fe}_{3} \mathrm{O}_{4}$ and $\mathrm{Au}-\mathrm{TiO}_{2} / \mathrm{SiO}_{2} @ \mathrm{Fe}_{3} \mathrm{O}_{4}$ nanocomposites, respectively.

The stability of the magnetic particles (i.e., iron oxides) was studied by measuring the photodissolution of the iron oxides using atomic absorption spectroscopy (ASA). As presented in Table 4, the concentration of iron in the reaction medium was below the limit of quantification $\left(1 \mathrm{mg} \cdot \mathrm{dm}^{-3}\right)$. The iron content for blank test, i.e., water without photocatalyst, equaled $0.49 \pm 0.06 \mathrm{mg} \cdot \mathrm{dm}^{-3} \mathrm{and}$ in post-reaction medium was about $0.55 \pm 0.10$. It has been previously reported that combining magnetite and titanium dioxide may lead to the photodissolution of iron oxide phase and the leaching of iron ions to reaction medium $[4,5]$. However, the introduction of a silica layer results in the prevention of iron oxide photodissolutions [56].

Table 4. Iron leaching to reaction medium.

\begin{tabular}{ccc}
\hline Photocatalysts & Iron Concentration $\left(\mathbf{m g} \cdot \mathbf{L}^{-\mathbf{l}}\right)$ & Comment \\
\hline $\mathrm{TiO}_{2} / \mathrm{SiO}_{2} @ \mathrm{Fe}_{3} \mathrm{O}_{4}$ & $0.55 \pm 0.08$ & $<\mathrm{LOQ}$ \\
$\mathrm{Cu}-\mathrm{TiO}_{2} / \mathrm{SiO}_{2} @ \mathrm{Fe}_{3} \mathrm{O}_{4}$ & $0.53 \pm 0.07$ & $<\mathrm{LOQ}$ \\
$\mathrm{Pd}-\mathrm{TiO}_{2} / \mathrm{SiO}_{2} @ \mathrm{Fe}_{3} \mathrm{O}_{4}$ & $0.50 \pm 0.08$ & $<\mathrm{LOQ}$ \\
$\mathrm{Pt}-\mathrm{TiO}_{2} / \mathrm{SiO}_{2} @ \mathrm{Fe}_{3} \mathrm{O}_{4}$ & $0.53 \pm 0.08$ & $<\mathrm{LOQ}$ \\
$\mathrm{Au}-\mathrm{TiO}_{2} / \mathrm{SiO}_{2} @ \mathrm{Fe}_{3} \mathrm{O}_{4}$ & $0.55 \pm 0.10$ & $<\mathrm{LOQ}$ \\
\hline
\end{tabular}

Additionally, a nanocomposite analysis of copper species dissolution for $\mathrm{Cu}-\mathrm{TiO}_{2} / \mathrm{SiO}_{2} @ \mathrm{Fe}_{3} \mathrm{O}_{4}$ was also performed. The content of $\mathrm{Cu}$ in post-reaction medium was defined as $0.41 \pm 0.08 \mathrm{mg} \cdot \mathrm{dm}^{-3}$. The obtained concentration was also below the limit of quantification $\left(0.5 \mathrm{mg} \cdot \mathrm{dm}^{-3}\right)$. Therefore, the obtained data clearly indicates that photocatalysts were stable during photocatalytic process and metal leaching was not observed.

\subsection{Identification of Degradation Intermediates}

Phenol is a non-volatile and common contaminant that is frequently present in industrial wastewaters. The US Environmental Protection Agency (EPA) and the European Union (EU) have classified phenolic compounds as priority pollutants since they are harmful to organisms even at low concentrations. Moreover, a higher content of phenol than $30 \mathrm{mg} \cdot \mathrm{dm}^{-3}$ inhibits biological treatment or even eliminates sensitive microorganisms from activated sludge in biological wastewater plants and significantly reduces the biodegradation of other components. Therefore, it is important to study the pathway and intermediates formed during the photo-oxidation of phenol. It is well known that catechol, hydroquinone and 1,4-benzoquinone are the three most important aromatic intermediates in the reaction of phenol degradation [57]. The oxidation route of phenol occurs by the hydroxylation of its molecule to hydroquinone and catechol as a first step with a further oxidation of the dihydroxylbenzenes to benzoquinones [57]. Similarly, in our study, the highest yield was observed for hydroquinone, and then catechol generation during phenol photocatalytic decomposition. As shown in Figure 6, the concentration of hydroquinone and p-benzoquinone in aqueous phase during $60 \mathrm{~min}$ of irradiation was much higher for $\mathrm{Au}-\mathrm{TiO}_{2} / \mathrm{SiO}_{2} @ \mathrm{Fe}_{3} \mathrm{O}_{4}$ than that for $\mathrm{Pd}-\mathrm{TiO}_{2} / \mathrm{SiO}_{2} @ \mathrm{Fe}_{3} \mathrm{O}_{4}$ and $\mathrm{Cu}-\mathrm{TiO}_{2} / \mathrm{SiO}_{2} @ \mathrm{Fe}_{3} \mathrm{O}_{4}$ photocatalysts, which revealed a significant enhancement of phenol photomineralization.

Generally, p-benzoquinone can be formed by (1) electrophilic attack of $\bullet \mathrm{OH}$ radical, (2) direct photooxidation of phenol by holes $\mathrm{h}^{+}$, which may form phenoxyl radical and directly oxidize phenol to benzoquinone, or (3) direct oxidation of hydroquinone by oxygen dissolved in water [57]. Hydroquinone could be produced directly by ${ }^{\bullet} \mathrm{OH}$ radical attack on a phenol molecule or by electron $\mathrm{e}_{\mathrm{cb}}{ }^{-}$reduction of benzoquinone molecule. Interestingly, catechol was not formed during the first $10 \mathrm{~min}$ of irradiation only on $\mathrm{Au}-\mathrm{TiO}_{2} / \mathrm{SiO}_{2} @ \mathrm{Fe}_{3} \mathrm{O}_{4}$ nanocomposite. It is proposed that keto-enol tautomeric equilibrium between hydroquinone and benzoquinone acts as a buffer and is responsible for the inhibition of phenol mineralization in the $\mathrm{Au}-\mathrm{TiO}_{2} / \mathrm{SiO}_{2} @ \mathrm{Fe}_{3} \mathrm{O}_{4}$ photocatalytic 
system [37]. The highest formation of catechol, the lowest amount of formed benzoquinone and lack of hydroquinone generation during first $10 \mathrm{~min}$ of irradiation was observed for the $\mathrm{Cu}-\mathrm{TiO}_{2} / \mathrm{SiO}_{2} @ \mathrm{Fe}_{3} \mathrm{O}_{4}$ photocatalyst, whereas, for $\mathrm{Pd}-\mathrm{TiO}_{2} / \mathrm{SiO}_{2} @ \mathrm{Fe}_{3} \mathrm{O}_{4}$ photocatalyst, a high yield of catechol and benzoquinone generation was determined in the reaction mixture. The oxalic acid (aliphatic intermediate) in the reaction mixture appeared after 10 min of irradiation for $\mathrm{Pd}-\mathrm{TiO}_{2} / \mathrm{SiO}_{2} @ \mathrm{Fe}_{3} \mathrm{O}_{4}$, and after $20 \mathrm{~min}$ for $\mathrm{Cu}$-, $\mathrm{Pt}$ - and unmodified- $\mathrm{TiO}_{2} / \mathrm{SiO}_{2} @ \mathrm{Fe}_{3} \mathrm{O}_{4}$, suggesting that the phenyl ring was destroyed, forming carboxylic acid intermediates through photocatalytic degradation. No oxalic acid generation was found for $\mathrm{Au}-\mathrm{TiO}_{2} / \mathrm{SiO}_{2} @ \mathrm{Fe}_{3} \mathrm{O}_{4}$ nanocomposite during 60 min of irradiation.
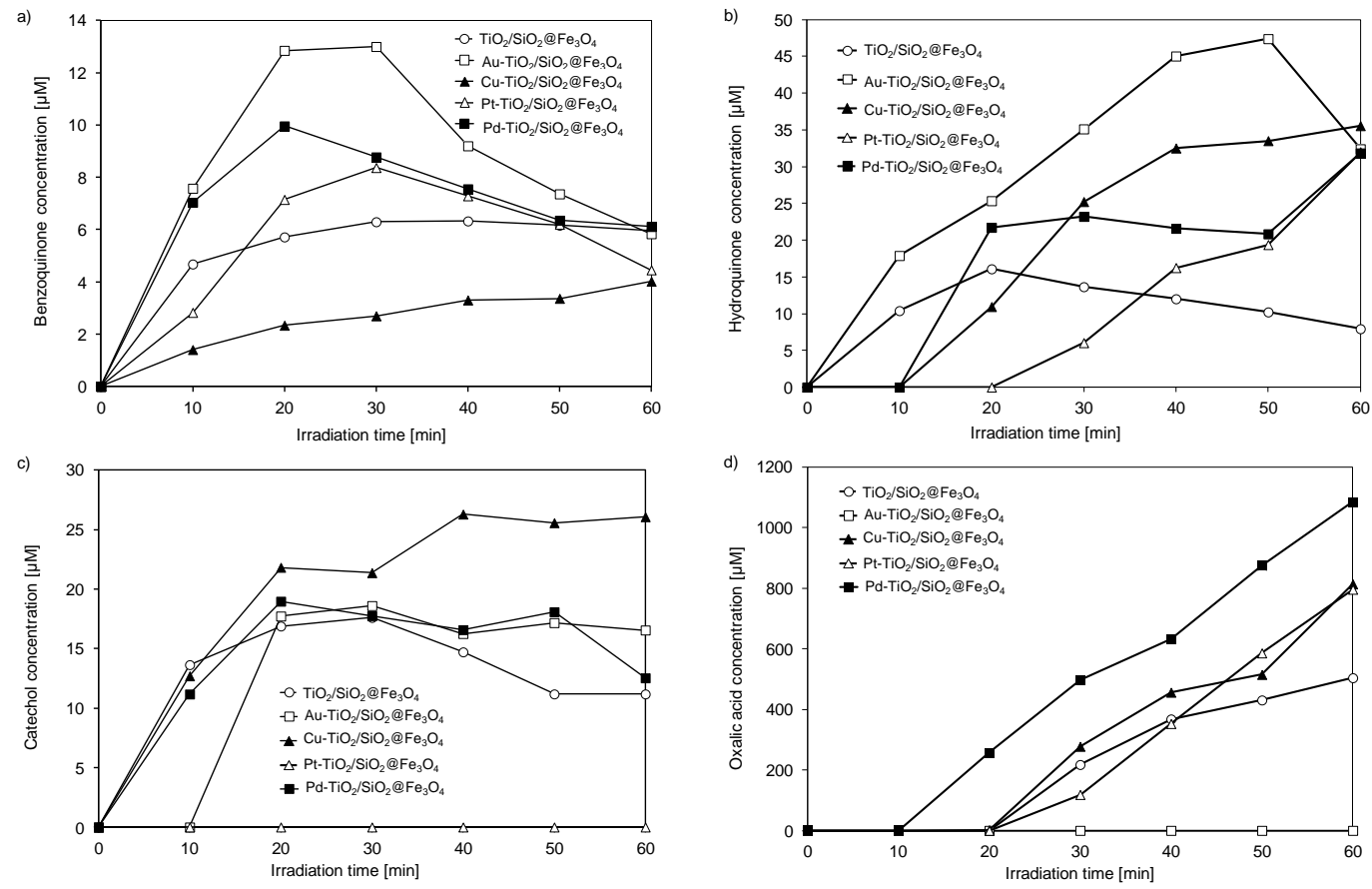

Figure 6. Variation of benzoquinone (a); hydroquinone (b); catechol (c) and oxalic acid (d) formation during phenol photodegradation.

For $\mathrm{Pt}-\mathrm{TiO}_{2} / \mathrm{SiO}_{2} @ \mathrm{Fe}_{3} \mathrm{O}_{4}$ photocatalyst only benzoquinone was detected in the first $10 \mathrm{~min}$ of irradiation, whereas after 20 min of irradiation, hydroquinone and oxalic acid were also formed. However, for platinum-modified photocatalyst, a significant change in the photoactivity with respect to $\mathrm{TiO}_{2} / \mathrm{SiO}_{2} @ \mathrm{Fe}_{3} \mathrm{O}_{4}$ nanocomposite was not noticed. Therefore, it is proposed that Pt particle sizes were probably decisive for the photocatalytic activity under UV-vis irradiation. Previously, we have reported that platinum deposited on anatase with a particle size below $3 \mathrm{~nm}$ exhibited the highest photocatalytic activity. Larger particles ( $>5 \mathrm{~nm}$ diameter) contained a decreased number of surface $\mathrm{Pt}$ atoms and therefore revealed decreased activity [48]. Platinum ions interact strongly with $\mathrm{TiO}_{2}$ matrix; therefore, the size of titania determines much more the size of platinum than palladium or copper.

To clarify the mechanism of phenol degradation, the analysis of hydroxyl radical formation on the surface of $\mathrm{Me}-\mathrm{TiO}_{2} / \mathrm{SiO}_{2} @ \mathrm{Fe}_{3} \mathrm{O}_{4}$ photocatalysts under UV-vis irradiation was performed by photoluminescence (PL) spectroscopy using terephtalic acid as a probe molecule. According to Figure 7, it was observed that obtained photocatalysts can produce ${ }^{\bullet} \mathrm{OH}$ under UV-vis light irradiation. After 60 min of irradiation, the highest amount of $\bullet \mathrm{OH}$ was observed for $\mathrm{Cu}-\mathrm{TiO}_{2} / \mathrm{SiO}_{2} @ \mathrm{Fe}_{3} \mathrm{O}_{4}$ nanocomposite, but modification with $\mathrm{Pd}$ resulted in a significant decrease in ${ }^{\bullet} \mathrm{OH}$ radical formation (much lower amount than that for unmodified nanocomposite).

The order of $\bullet \mathrm{OH}$ radical formation on magnetic photocatalysts was as follows: $\mathrm{Cu}-\mathrm{TiO}_{2} / \mathrm{SiO}_{2} @ \mathrm{Fe}_{3} \mathrm{O}_{4}>\mathrm{Pt}-\mathrm{TiO}_{2} / \mathrm{SiO}_{2} @ \mathrm{Fe}_{3} \mathrm{O}_{4}>\mathrm{TiO}_{2} / \mathrm{SiO}_{2} @ \mathrm{Fe}_{3} \mathrm{O}_{4}>\mathrm{Au}-\mathrm{TiO}_{2} / \mathrm{SiO}_{2} @ \mathrm{Fe}_{3} \mathrm{O}_{4}$ $>\mathrm{Pd}-\mathrm{TiO}_{2} / \mathrm{SiO}_{2} @ \mathrm{Fe}_{3} \mathrm{O}_{4}$, suggesting that the mechanism of phenol degradation on the 
$\mathrm{Cu}-\mathrm{TiO}_{2} / \mathrm{SiO}_{2} @ \mathrm{Fe}_{3} \mathrm{O}_{4}$ photocatalyst mainly proceeded by the attack of hydroxyl radicals on the phenyl ring, leading to catechol formation, then being further oxidized to oxalic acid and mineralized to $\mathrm{CO}_{2}$. Whereas the obtained results for $\mathrm{Pd}-\mathrm{TiO}_{2} / \mathrm{SiO}_{2} @ \mathrm{Fe}_{3} \mathrm{O}_{4}$ indicated that phenol photocatalytic degradation was attributed to other forms of reactive oxygen species (ROS) e.g., ${ }^{\bullet} \mathrm{O}_{2}{ }^{2-},{ }^{\bullet} \mathrm{O}_{2}{ }^{-},{ }^{1} \mathrm{O}_{2}$ and $\mathrm{H}_{2} \mathrm{O}_{2}$. In order to confirm the role of generated ROS during photocatalytic reaction on the surface of $\mathrm{Me}-\mathrm{TiO}_{2} / \mathrm{SiO}_{2} @ \mathrm{Fe}_{3} \mathrm{O}_{4}$ photocatalysts, the phenol degradation tests were conducted in the presence of $\mathrm{e}_{\mathrm{cb}}{ }^{-}, \mathrm{h}^{+},{ }^{\bullet} \mathrm{O}_{2}{ }^{-}$and ${ }^{\bullet} \mathrm{OH}$ scavengers, and under anaerobic conditions $\left(\mathrm{N}_{2}\right.$ purging).

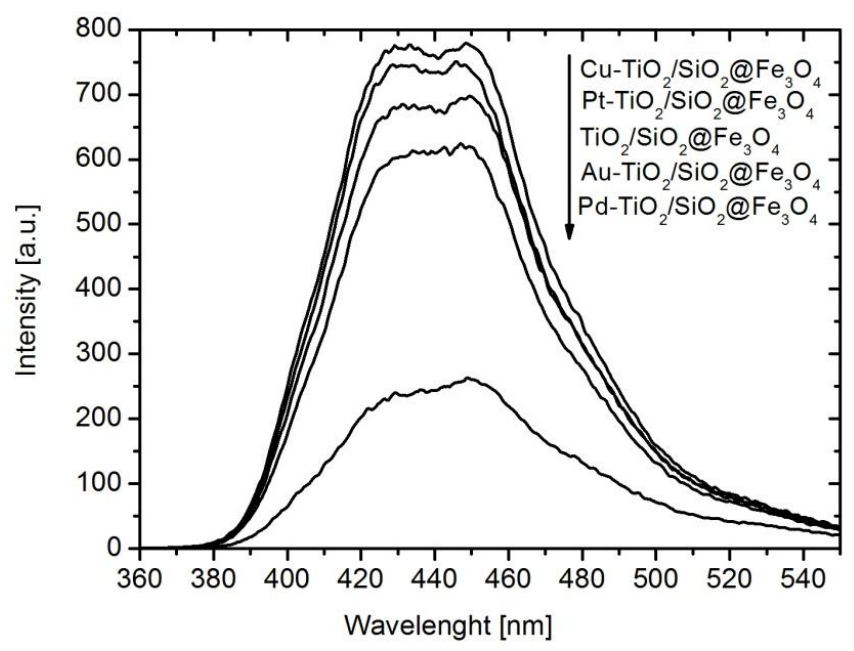

Figure 7. Fluorescence spectra changes observed during irradiation of $\mathrm{Me}-\mathrm{TiO}_{2} / \mathrm{SiO}_{2} @ \mathrm{Fe}_{3} \mathrm{O}_{4}$ photocatalysts under UV-Vis irradiation.

\subsection{Verification of the Degradation Mechanism Using Scavengers and Under $\mathrm{N}_{2}$ Purging}

The active species were investigated to understand the photocatalytic reaction mechanism. The holes $\left(\mathrm{h}^{+}\right)$, hydroxyl radicals $\left({ }^{\bullet} \mathrm{OH}\right)$ and superoxide radical anion $\left({ }^{\bullet} \mathrm{O}_{2}{ }^{-}\right)$are the probable active species taking part in the photodegradation of organic pollutants. Results of the photocatalytic activity in reaction of phenol degradation in the presence of $\mathrm{e}^{-}, \mathrm{h}^{+},{ }^{\bullet} \mathrm{O}_{2}{ }^{-}$and ${ }^{\bullet} \mathrm{OH}$ scavengers, i.e., silver nitrate, ammonium oxalate, benzoquinone and tert-butyl alcohol, respectively, and during $\mathrm{N}_{2}$ purging are presented in Figure 8.

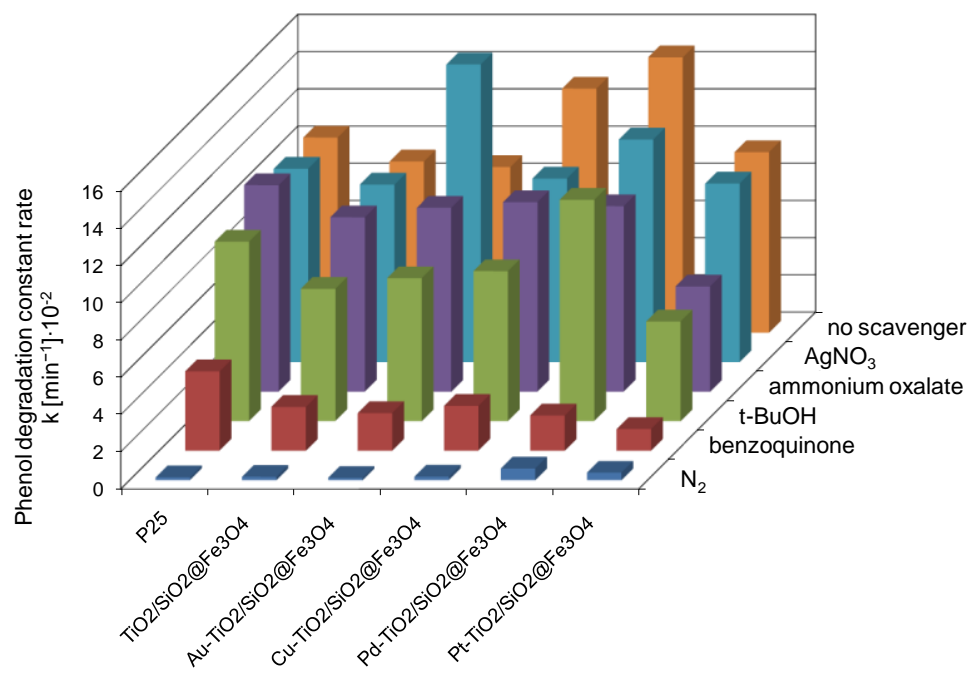

Figure 8. Photocatalytic degradation of phenol for $\mathrm{Me}-\mathrm{TiO}_{2} @ \mathrm{SiO}_{2} / \mathrm{Fe}_{3} \mathrm{O}_{4}$ photocatalysts in the presence of $\mathrm{e}^{-}, \mathrm{h}^{+}, \bullet^{\bullet} \mathrm{O}_{2}^{-}$and $\bullet \mathrm{OH}^{-}$scavengers and $\mathrm{N}_{2}$ purging. 
The degradation constant rates, determined without scavengers, serve as reference materials for particular photocatalysts. In the presence of no scavenger, the highest activity was exhibited by $\mathrm{Pd}-\mathrm{TiO}_{2} / \mathrm{SiO}_{2} @ \mathrm{Fe}_{3} \mathrm{O}_{4}$ and $\mathrm{Cu}-\mathrm{TiO}_{2} / \mathrm{SiO}_{2} @ \mathrm{Fe}_{3} \mathrm{O}_{4}$ photocatalysts. The lowest activity was found for $\mathrm{SiO}_{2} @ \mathrm{Fe}_{3} \mathrm{O}_{4}$, with a degradation constant rate of $0.84 \times 10^{-2} \mathrm{~min}^{-1}$. Compared to metal-modified $\mathrm{TiO}_{2} / \mathrm{SiO}_{2} @ \mathrm{Fe}_{3} \mathrm{O}_{4}$ nanoparticles, the activity of silica-magnetite nanocomposite was negligible, and therefore no further experiments were carried out for this sample. The low activity of $\mathrm{SiO}_{2} @ \mathrm{Fe}_{3} \mathrm{O}_{4}$ indicates that, despite the presence of ferric ions in the structure of nanocomposite, the photocatalytic activity results only from the presence of $\mathrm{TiO}_{2}$ on the surface of magnetic nanocomposite, whereas $\mathrm{SiO}_{2} @ \mathrm{Fe}_{3} \mathrm{O}_{4}$ plays the role for an inert structure.

\subsubsection{Effect of $\mathrm{N}_{2}$ Purging}

Molecular oxygen dissolved in water solution acts as an electron acceptor in photodegradation process, which limits the recombination rate between electron and hole through the formation of reactive oxygen species. In this study, the effect of dissolved oxygen was investigated by $\mathrm{N}_{2}$ purging. As shown in Figure 8, the decrease concentration of oxygen in reaction solution resulted in inhibition of phenol degradation for all obtained magnetic photocatalysts. This observation demonstrates the predominant role of reactive oxygen species in mechanism of phenol degradation.

\subsubsection{Effect of Benzoquinone}

To identify the contribution of superoxide radical species on the photocatalytic degradation, prior to irradiation $500 \mathrm{mg} \cdot \mathrm{dm}^{-3}$ of benzoquinone (BQ) was added into phenol solution. The photocatalytic performance was significantly suppressed after $\mathrm{BQ}$ was introduced, indicating that ${ }^{\bullet} \mathrm{O}_{2}{ }^{-}$played a crucial role in the photodegradation process. Phenol degradation efficiency was reduced by $88 \%$ for $\mathrm{Pt}-\mathrm{TiO}_{2} / \mathrm{SiO}_{2} @ \mathrm{Fe}_{3} \mathrm{O}_{4}$ and $\mathrm{Pd}-\mathrm{TiO}_{2} / \mathrm{SiO}_{2} @ \mathrm{Fe}_{3} \mathrm{O}_{4}$ photocatalysts. For $\mathrm{Au}-\mathrm{TiO}_{2} / \mathrm{SiO}_{2} @ \mathrm{Fe}_{3} \mathrm{O}_{4}$, $\mathrm{Cu}-\mathrm{TiO}_{2} / \mathrm{SiO}_{2} @ \mathrm{Fe}_{3} \mathrm{O}_{4}$ and $\mathrm{TiO}_{2} / \mathrm{SiO}_{2} @ \mathrm{Fe}_{3} \mathrm{O}_{4}$ nanocomposites, the addition of BQ inhibited the photocatalytic efficiency by $75-77 \%$ and slightly lower for $\mathrm{TiO}_{2} \mathrm{P} 25(60 \%)$.

\subsubsection{Effect of $\mathrm{t}-\mathrm{BuOH}$}

The tert-butyl alcohol $(\mathrm{t}-\mathrm{BuOH})$ was utilized to trap the photogenerated hydroxyl radical $\left(\bullet^{\bullet} \mathrm{OH}\right)$. The introduction of $\mathrm{t}-\mathrm{BuOH}$ resulted in decrease of phenol degradation constant rate mainly for $\mathrm{Pt}-\mathrm{TiO}_{2} / \mathrm{SiO}_{2} @ \mathrm{Fe}_{3} \mathrm{O}_{4}$ and $\mathrm{Cu}-\mathrm{TiO}_{2} / \mathrm{SiO}_{2} @ \mathrm{Fe}_{3} \mathrm{O}_{4}$ nanocomposites. The degradation constant rate was $45 \%$ and $38 \%$ lower than without tert-butyl alcohol and equalled $5.36 \times 10^{-2}$ and $8.06 \times 10^{-2} \mathrm{~min}^{-1}$ for $\mathrm{Pt}-\mathrm{TiO}_{2} / \mathrm{SiO}_{2} @ \mathrm{Fe}_{3} \mathrm{O}_{4}$ and $\mathrm{Cu}-\mathrm{TiO}_{2} / \mathrm{SiO}_{2} @ \mathrm{Fe}_{3} \mathrm{O}_{4}$, respectively. Less affected by t-BuOH scavenger was $\mathrm{Pd}-\mathrm{TiO}_{2} / \mathrm{SiO}_{2} @ \mathrm{Fe}_{3} \mathrm{O}_{4}$ magnetic photocatalyst and $\mathrm{TiO}_{2} \mathrm{P} 25$. A decrease in phenol degradation constant rate from $14.8 \times 10^{-2}$ to $11.97 \times 10^{-2} \mathrm{~min}^{-1}$ was observed for $\mathrm{Pd}-\mathrm{TiO}_{2} / \mathrm{SiO}_{2} @ \mathrm{Fe}_{3} \mathrm{O}_{4}$ and from $10.49 \times 10^{-2}$ to $9.65 \times 10^{-2} \mathrm{~min}^{-1}$ for $\mathrm{TiO}_{2} \mathrm{P} 25$.

\subsubsection{Effect of Ammonium Oxalate}

Ammonium oxalate was introduced as the scavenger of photogenerated holes $\left(\mathrm{h}^{+}\right)$. The photodegradation reaction was partly suppressed by $33 \%$ and $42 \%$ for $\mathrm{Pd}-\mathrm{TiO}_{2} / \mathrm{SiO}_{2} @ \mathrm{Fe}_{3} \mathrm{O}_{4}$ and $\mathrm{Pt}-\mathrm{TiO}_{2} / \mathrm{SiO}_{2} @ \mathrm{Fe}_{3} \mathrm{O}_{4}$ nanocomposites, suggesting that $\mathrm{h}^{+}$also played a role in the process of phenol oxidation. For $\mathrm{Cu}-\mathrm{TiO}_{2} / \mathrm{SiO}_{2} @ \mathrm{Fe}_{3} \mathrm{O}_{4}, \mathrm{Au}-\mathrm{TiO}_{2} / \mathrm{SiO}_{2} @ \mathrm{Fe}_{3} \mathrm{O}_{4}, \mathrm{TiO}_{2} / \mathrm{SiO}_{2} @ \mathrm{Fe}_{3} \mathrm{O}_{4}$ and $\mathrm{TiO}_{2} \mathrm{P} 25$ photocatalysts, ammonium oxalate capturing of $\mathrm{h}^{+}$have little or almost no effect on the efficiency of phenol degradation. Thus, $\mathrm{h}^{+}$is not the important active species for the reaction of phenol degradation in the presence of $\mathrm{P} 25, \mathrm{TiO}_{2} / \mathrm{SiO}_{2} @ \mathrm{Fe}_{3} \mathrm{O}_{4}$ and $\mathrm{TiO}_{2} / \mathrm{SiO}_{2} @ \mathrm{Fe}_{3} \mathrm{O}_{4}$ modified by copper or gold nanoparticles. 


\subsubsection{Effect of Silver Nitrate}

Silver nitrate was utilized to trap the photogenerated electrons. The phenol degradation for $\mathrm{TiO}_{2} \mathrm{P} 25, \mathrm{Cu}-\mathrm{TiO}_{2} / \mathrm{SiO}_{2} @ \mathrm{Fe}_{3} \mathrm{O}_{4}, \mathrm{Pt}-\mathrm{TiO}_{2} / \mathrm{SiO}_{2} @ \mathrm{Fe}_{3} \mathrm{O}_{4}$ and $\mathrm{Pd}-\mathrm{TiO}_{2} / \mathrm{SiO}_{2} @ \mathrm{Fe}_{3} \mathrm{O}_{4}$ photocatalysts in the presence of $\mathrm{AgNO}_{3}$ caused a negligible decrease in the photocatalytic efficiency. Moreover, for $\mathrm{TiO}_{2} / \mathrm{SiO}_{2} @ \mathrm{Fe}_{3} \mathrm{O}_{4}$ and $\mathrm{Au}-\mathrm{TiO}_{2} / \mathrm{SiO}_{2} @ \mathrm{Fe}_{3} \mathrm{O}_{4}$ photocatalysts, the addition of silver ions has a rate-enhancing effect. $\mathrm{Ag}^{+}$ion could trap photogenerated electrons to avoid the recombination of electrons and holes. The positive effect of electron trapping may also result from the in-situ formation of bimetallic particles of Ag-Au deposited on the surface of $\mathrm{TiO}_{2} / \mathrm{SiO}_{2} @ \mathrm{Fe}_{3} \mathrm{O}_{4}$ nanocomposite. It was reported that such coupling of $\mathrm{Ag}$ and $\mathrm{Au}$ increases the photocatalytic performance of the photocatalyst [58,59].

These results confirm the crucial role of reactive oxygen species $\left({ }^{\bullet} \mathrm{O}_{2}{ }^{-}\right.$and $\left.{ }^{\bullet} \mathrm{OH}\right)$ in the photocatalytic degradation of phenol in the presence of $\mathrm{Me}-\mathrm{TiO}_{2} / \mathrm{SiO}_{2} @ \mathrm{Fe}_{3} \mathrm{O}_{4}$ photocatalysts.

\section{Discussion and Proposed Mechanism}

The degradation of organic pollutants proceeds through the formation of intermediates, which often are very stable and toxic for the environment. In order to do the above, it is essential to investigate the mechanism of pollutant degradation. Of particular interest should be studies on correlation between activity, composition and selectivity of photocatalysts.

Oxidation or reduction pathways of $\mathrm{TiO}_{2}$-based photocatalytic reaction may depend on the crystalline structure, surface or bulk modification of semiconductor, $\mathrm{pH}$ and salinity of the surrounded medium [60-62].

The first step of photocatalytic reaction involves excitation of $\mathrm{TiO}_{2}$. Photogenerated hole and electron pairs may recombine or migrate on the semiconductor surface, taking part in reaction with water, oxygen and other species present on the $\mathrm{TiO}_{2}$ surface or in the surrounded medium. However, the adsorbed molecules may be oxidized via direct or indirect methods [63]. A direct oxidation proceeded through the reaction of free holes/electrons with adsorbed organics, while an indirect oxidation proceeds through oxidation by reactive oxygen species (ROS). ROS are formed, depending on the $\mathrm{pH}$ of surrounding solution, by reaction of photogenerated holes with terminal oxygen ions or terminal hydroxyl groups. ROS may be also generated during a recombination of organic radicals. In our study, the $\mathrm{pH}$ of the aqueous phase was slightly basic, indicating $\left(\mathrm{pH}>\mathrm{pH}_{\text {IEP }}\right)$ formation mainly of superoxide radicals. Miyazaki et al. [64] observed that, at room temperature, the generation of dihydroxybenzenes is favored during both direct and indirect oxidation. Kim and Choi [35] observed that photocatalytic activity of phenols may be also affected by the formation of surface complexes of adsorbed molecule and terminal titanium atoms. They proposed that the complex formation included covalent bonding as well as physical adsorption and depended on the surface area affected by $\mathrm{TiO}_{2}$ structure. The complex formation could induce visible light activity, whereas, under $\mathrm{UV}$ light, hydroxyl radical generation played the main role. The formation of $\mathrm{TiO}_{2}$-organic molecule complex was observed for bare titanium(IV) oxide $\mathrm{P} 25$, while for $\mathrm{Pt}_{-} \mathrm{TiO}_{2}$ and $\mathrm{F}-\mathrm{TiO}_{2}$ the complexation did not occur, due to blocking Ti-OH sites and the changing acidity of $\mathrm{OH}$ groups. Murcia et al. [65] have also investigated the formation of surface complex on $\mathrm{Pt}_{-} \mathrm{TiO}_{2}$ surface. They observed that platinum nanoparticles favored the adsorption of phenol on photocatalyst surface by the formation of bidentate phenolates species. The adsorption depended on platinum NP size and the oxidation state of Pt species [65]. Small palladium nanoparticles preferentially are formed on lattice defects. Similarly, our previous studies for $\mathrm{Ag} / \mathrm{Au}$-, $\mathrm{Pt} / \mathrm{Pd}$ - and $\mathrm{Ag} / \mathrm{Pt}$-modified $\mathrm{TiO}_{2}$ showed the dependence of particle size of platinum and gold NPs on the crystallite size of titania particles, where small anatase with a larger number of surface defects than that in well crystallized larger particles of rutile and anatase stimulated formation of fine noble metal nanoparticles $[48,59,66]$.

Combining the obtained results, a possible mechanism for the photocatalytic degradation of phenol with metal-modified $(\mathrm{Me}=\mathrm{Pd}, \mathrm{Pt}, \mathrm{Cu}, \mathrm{Au}) \mathrm{TiO}_{2} / \mathrm{SiO}_{2} @ \mathrm{Fe}_{3} \mathrm{O}_{4}$ photocatalysts is proposed and illustrated in Figure 9. For $\mathrm{Cu}-\mathrm{TiO}_{2} / \mathrm{SiO}_{2} @ \mathrm{Fe}_{3} \mathrm{O}_{4}$, superoxide and hydroxyl radicals are 
mainly active species involved in phenol degradation, which attack the phenyl ring yielding catechol, and hydroquinone generation (benzoquinone was also detected but at significantly lower concentration). Then, the phenyl rings in these compounds disintegrate and short-chain organic acids are produced, mainly oxalic acid, which further mineralized to $\mathrm{CO}_{2}$ and $\mathrm{H}_{2} \mathrm{O}$ (see Figure 9a). For $\mathrm{Au}-\mathrm{TiO}_{2} / \mathrm{SiO}_{2} @ \mathrm{Fe}_{3} \mathrm{O}_{4}$, the surface plasmon resonance induces electrons to be transferred to the conduction band of $\mathrm{TiO}_{2}$ and are trapped by dissolved oxygen, resulting in generation of ${ }^{-} \mathrm{O}_{2}{ }^{-}$. The main intermediates determined in the first minutes of irradiation are benzoquinone and hydroquinone. However, the induction period was observed for generation of catechol by oxidation of phenol in the presence of $\mathrm{h}_{\mathrm{vb}}{ }^{+}$. As shown in Figure $9 \mathrm{~b}$, the keto-enol tautomeric equilibrium between hydroquinone and benzoquinone retards the rate of phenol photomineralization.

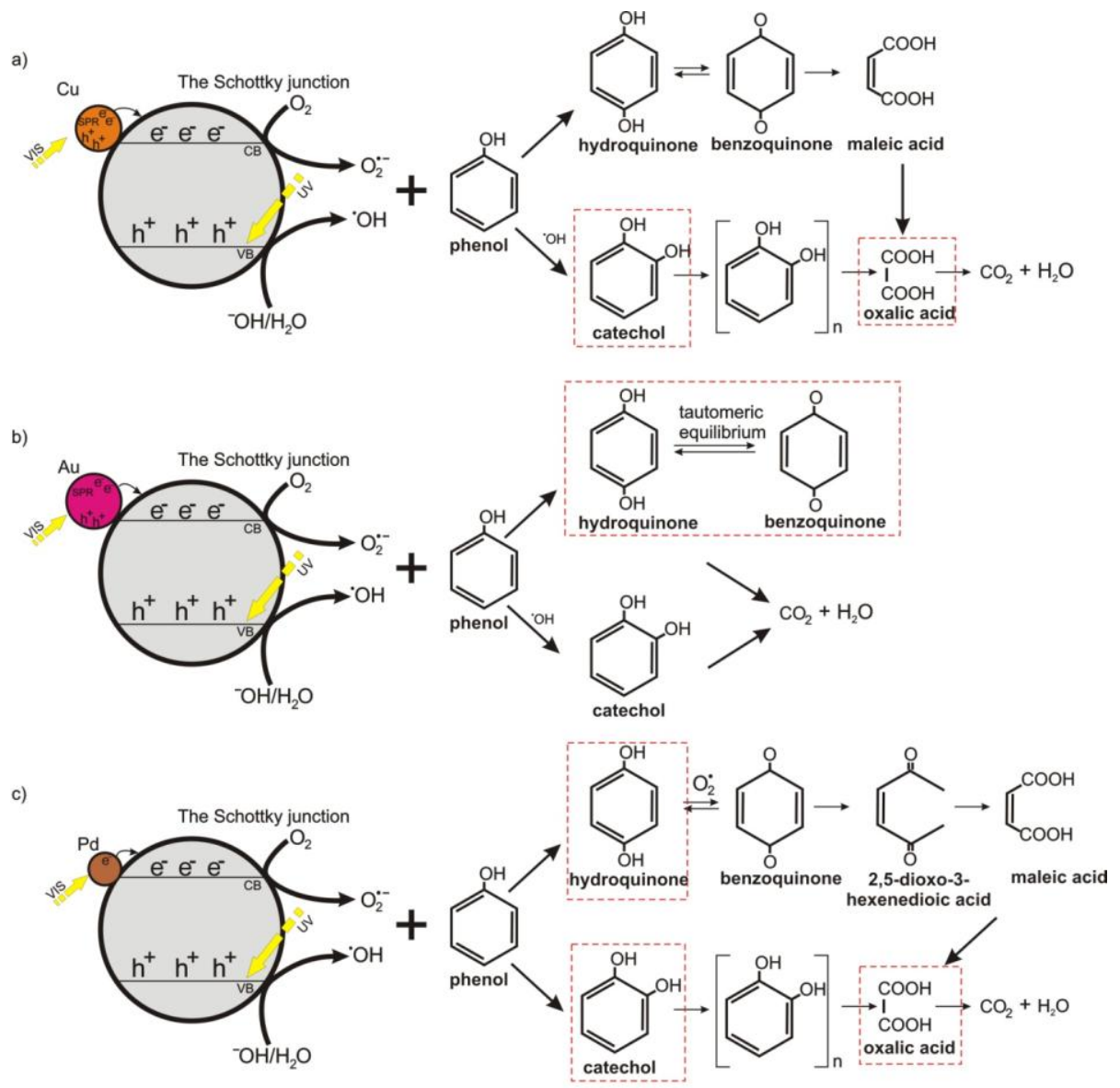

d)

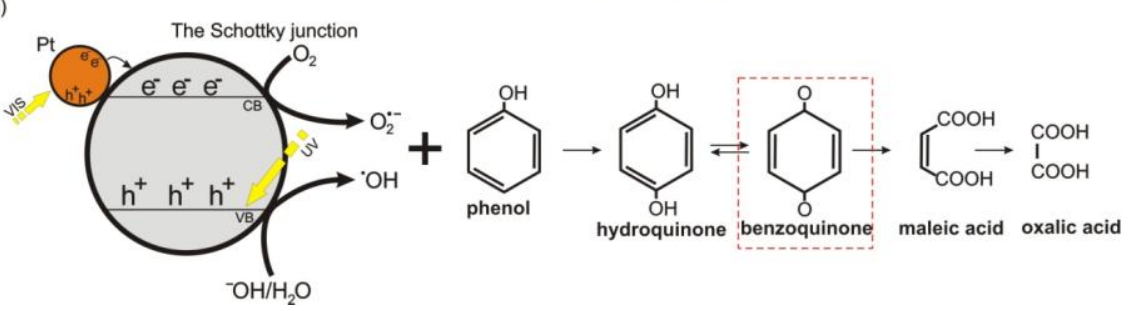

Figure 9. Schematic illustration of the phenol photocatalytic degradation mechanism for magnetic photocatalysts modified with: (a) copper; (b) gold; (c) palladium and (d) platinum nanoparticles.

The mechanism of phenol degradation in the presence of $\mathrm{Pd}-\mathrm{TiO}_{2} / \mathrm{SiO}_{2} @ \mathrm{Fe}_{3} \mathrm{O}_{4}$ photocatalyst proceeds by generation of reactive oxygen species, e.g., ${ }^{\bullet} \mathrm{O}_{2}{ }^{-}$, which oxidize phenol to benzoquinone, hydroquinone and catechol (see in Figure 9c). The highest concentration of benzoquinone and hydroquinone was observed at the beginning of the reaction. However, hydroquinone 
concentration decreased slower compared to the catechol amount due to different pathways of phenol photo-oxidation. Our observations are in good agreement with literature. Santos et al. [67] found that catechol oxidation did not yield either benzoquinone or maleic acid formation, but oxalic acid, which finally was mineralized to $\mathrm{CO}_{2}$. However, benzoquinone and maleic acid are products, which are determined in the hydroquinone oxidation. The induction period for hydroquinone oxidation was reported, meaning that fewer or more-quickly oxidizable intermediates are produced from catechol than from hydroquinone [67]. In our study, a much higher mineralization rate was observed for $\mathrm{Pd}-\mathrm{TiO}_{2} / \mathrm{SiO}_{2} @ \mathrm{Fe}_{3} \mathrm{O}_{4}$ and $\mathrm{Cu}-\mathrm{TiO}_{2} / \mathrm{SiO}_{2} @ \mathrm{Fe}_{3} \mathrm{O}_{4}$ photocatalysts, which produced the highest concentration of catechol during photocatalytic reaction. For $\mathrm{Pt}-\mathrm{TiO}_{2} / \mathrm{SiO}_{2} @ \mathrm{Fe}_{3} \mathrm{O}_{4}$ nanocomposite, catechol was not detected after 60 min of irradiation, resulting in a low oxidation to oxalic acid and mineralization to $\mathrm{CO}_{2}$ (see in Figure 9d). Therefore, it is proposed that enhanced activity is related to a decrease in palladium particle size, an increase in adsorption sites and efficient separation of charge carriers.

\section{Materials and Methods}

\subsection{Materials and Instruments}

Commercial $\mathrm{TiO}_{2}$ P25 (a mixture of the crystalline phases: anatase (73-85\%), rutile (14-17\%), and amorphous titania (0-13\%) [1,2], Brunauer-Emmett-Tellersurface area $\mathrm{S}_{\mathrm{BET}}=50 \mathrm{~m}^{2} \cdot \mathrm{g}^{-1}$ supplier: Evonik, Essen, Germany) was used for the preparation of $\mathrm{Me}-\mathrm{TiO}_{2} / \mathrm{SiO}_{2} @ \mathrm{Fe}_{3} \mathrm{O}_{4}$ photocatalysts. Ferrous ferric oxide $\left(\mathrm{Fe}_{3} \mathrm{O}_{4}, 97 \%\right)$ with particle size of about $50 \mathrm{~nm}$ was purchased from Aldrich (St. Louis, MO, USA) and used as a magnetic core of obtained $\mathrm{Me}-\mathrm{TiO}_{2} / \mathrm{SiO}_{2} @ \mathrm{Fe}_{3} \mathrm{O}_{4}$ nanocomposites. Ethyl alcohol (99.8\%) was used as solvent and tetraethyl orthosilicate (TEOS, $\left.\left.\mathrm{Si}\left(\mathrm{OC}_{2} \mathrm{H}_{5}\right)_{4}\right), 99 \%\right)$, provided by Aldrich (St. Louis, MO, USA), was used as starting material for the preparation of $\mathrm{SiO}_{2} @ \mathrm{Fe}_{3} \mathrm{O}_{4}$ nanoparticles. Ammonium hydroxide solution (25\%) was purchased from Avantor (Center Valley, PA, USA). Gold(III) chloride, copper(II) nitrate, palladium(II) chloride, chloroplatinic acid hexahydrate and sodium borohydride were provided by Aldrich and used as starting materials for preparation of metallic nanoparticles (NPs) deposited on $\mathrm{TiO}_{2} / \mathrm{SiO}_{2} @ \mathrm{Fe}_{3} \mathrm{O}_{4}$. Phenol (99.5\%) was provided by Aldrich (St. Louis, MO, USA) and used as model organic pollutant. Intermediates of photocatalytic phenol decomposition e.g., benzoquinone, hydroquinone, catechol, maleic acid and oxalic acid were purchased from Fluka (Shanghai, China) and used for quantitative determination of their concentration during photodegradation process. Charge carrier scavengers, such as ammonium oxalate, silver nitrate, butyl alcohol and benzoquinone were provided by Aldrich (St. Louis, MO, USA). All reagents were used without further purification.

XRD analysis was performed using a Rigaku Intelligent X-ray diffraction system (SmartLab, Neu-Isenburg, Germany) equipped with a sealed tube X-ray generator (Neu-Isenburg, Germany). Measurements were performed on the $2 \theta$ range of $10-80^{\circ}$ with the scan speed of $1.00^{\circ} \cdot \mathrm{min}^{-1}$ and scan step of $0.01^{\circ}$. Crystallite size of photocatalysts in the direction vertical to the corresponding lattice plane was determined using the Scherrer equation, based on the corrected full width at half maximum (FWHM) of the XRD peak and angle of diffraction.

To characterise the light-absorption properties of modified photocatalysts, diffuse reflectance (DR) spectra were recorded, and data were converted to obtain absorption spectra. To characterise the light-absorption properties of modified photocatalysts, diffuse reflectance (DR) spectra were recorded, and data were converted to obtain absorption spectra. The band gap energy of photocatalysts was calculated from the corresponding Kubelka-Munk function, $F(R)^{0.5} E_{\mathrm{ph}}^{0.5}$ against $E_{\mathrm{ph}}$, where $E_{\mathrm{ph}}$ is photon energy. The measurements were carried out on ThemoScientific (Waltham, MA, USA) evolution 220 spectrophotometer equipped with PIN-757 integrating sphere (Waltham, MA, USA). Commercial $\mathrm{TiO}_{2}$ P25 was used as a reference sample.

XPS analysis was carried out in multichamber ultrahigh vacuum (UHV) system (Omicron nanoTechnology, Taunusstein, Germany), at room temperature in a ultra-high vacuum conditions, 
below $1.1 \times 10^{-8} \mathrm{mBar}$. The photoelectrons were excited by an $\mathrm{Mg}-\mathrm{K}_{\alpha} \mathrm{X}$-Ray source. The X-ray anode was operated at $15 \mathrm{keV}$ and $300 \mathrm{~W}$. Omicron Argus hemispherical electron analyser with round aperture of $4 \mathrm{~mm}$ was used for analysis of emitted photoelectrons. Measurements were carried out in a constant analyser energy (CAE) mode with pass energy equal $50 \mathrm{eV}$. The binding energies were corrected using the background C 1s line (285.0 eV) as a reference. XPS spectra were analysed with Casa-XPS software (Prevac, Rogów, Poland) using a Shirley background subtraction and Gaussian-Lorentzian curve as a fitting algorithm.

The particle size, dispersion uniformity and chemical composition of obtained nanocomposites was examined using transmission electron microscopy (HRTEM) using FEI Europe, Tecnai F20 X-Twin (Waltham, MA, USA).

Magnetic hysteresis loops were carried out using psychical properties measurements system (PPMS, Quantum Design, San Diego, CA, USA). Measurements were performed at temperature of $293 \mathrm{~K}$, in the range of 0-30,000 Oe.

Electrochemical impedance spectroscopy (EIS) measurements were performed using the potentiostat-galvanostat AutoLab PGStat302N system (Utrecht, The Netherlands) under GPES/FRA software control. Electrochemical experiments were performed in a three-electrode cell in $0.2 \mathrm{M} \mathrm{K}_{2} \mathrm{SO}_{4}$ in $\mathrm{pH}$ adjusted to $7 . \mathrm{Ag} / \mathrm{AgCl}(0.1 \mathrm{M} \mathrm{KCl})$ was used as a reference electrode and platinum mesh acted as a counter electrode. The impedance spectra were taken at the frequency range from $10 \mathrm{kHz}$ to $100 \mathrm{~Hz}$ with $10 \mathrm{mV}$ amplitude of the alternating current.

AC signal. Space charge region capacitances have been calculated from single frequency $(1000 \mathrm{~Hz})$ using Equation (1).

$$
C_{\mathrm{sc}}=-\frac{1}{Z^{\prime \prime} \omega}
$$

$C$ - capacitance, $Z^{\prime \prime}$-imaginary impedance, $\omega$-angular frequency.

Mott-Schottky analysis was performed in order to examine the influence of metal nanoparticles on the flat band potential of metal-modified $\mathrm{TiO}_{2}$. Flat band potential can be estimated from intercept of $C_{\mathrm{sc}}{ }^{-2}$ vs. $E$, according to Equation (2) assuming that the term $\mathrm{k}_{\mathrm{B}} T / e$ is small and can be neglected, where

$$
C_{\mathrm{sc}}^{-2}=\left(\frac{2}{\varepsilon \varepsilon_{0} \mathrm{eN} \mathrm{N}_{\mathrm{D}}}\right)\left(E-E_{f b}-\frac{\mathrm{k}_{\mathrm{B}} T}{\mathrm{e}}\right)
$$

$\mathrm{C}_{\mathrm{sc}}$ - capacitance of space charge region, $\varepsilon$ and $\varepsilon_{0}$ - dielectric constant of the material and permittivity of free space, e-electronic charge, $\mathrm{N}_{\mathrm{D}}$ - the number of donors, E-applied potential, $E_{f b}$-flat band potential, $\mathrm{k}_{\mathrm{B}}$-Boltzmann's constant, $T$-temperature.

Impedance spectra analysis and fitting were performed using EIS Spectrum Analyzer software.

Atomic absorbance spectroscopy (AAS) measurements were performed using SENS AA DUAL spectrometer (GBC EQUIPMENT, Hampshire, IL, USA) equipped with hollow cathodic lamps Cu (GBC EQUIPMENT) and Fe (CPI International, Palo Alto, CA, USA).

\subsection{Preparation of $\mathrm{TiO}_{2} / \mathrm{SiO}_{2} @ \mathrm{Fe}_{3} \mathrm{O}_{4}$ and $\mathrm{Me}-\mathrm{TiO}_{2} / \mathrm{SiO}_{2} @ \mathrm{Fe}_{3} \mathrm{O}_{4}$ Photocatalysts}

$\mathrm{TiO}_{2} / \mathrm{SiO}_{2} @ \mathrm{Fe}_{3} \mathrm{O}_{4}$ nanocomposites were prepared by an ultrasonic-assisted sol-gel method. Firstly, $1 \mathrm{~g}$ of commercial $\mathrm{Fe}_{3} \mathrm{O}_{4}$ magnetic nanoparticles was dispersed in $50 \mathrm{~cm}^{3}$ of ethanol and ultrasonicated for $15 \mathrm{~min}$. Subsequently, $100 \mathrm{~cm}^{3}$ of ethanol and $20 \mathrm{~cm}^{3}$ of water were added to the suspension and sonicated for $30 \mathrm{~min}$. Then, $150 \mathrm{~cm}^{3}$ of ammonia ethanolic solution was dropwise added into magnetite dispersion and sonicated for another $15 \mathrm{~min}$. In the next step, $7.71 \mathrm{~cm}^{3}$ of tetraethyl orthosilicate (TEOS), preliminarily diluted in ethanol, was added to the magnetite particles suspension and ultrasonicated for the next $15 \mathrm{~min}$. The weight ratio of magnetite to titanium(IV) oxide was equal to 1:2, whereas molar ratios of TEOS to $\mathrm{Fe}_{3} \mathrm{O}_{4}$ and $\mathrm{NH}_{4} \mathrm{OH}$ to TEOS were 8:1 and 16:1, respectively. After aging of silica gel the suspension of commercial $\mathrm{TiO}_{2}$ (P25) in $50 \mathrm{~cm}^{3}$ of ethanol was added into $\mathrm{SiO}_{2} @ \mathrm{Fe}_{3} \mathrm{O}_{4}$ dispersion and stirred for $2 \mathrm{~h}$. The obtained suspension of $\mathrm{TiO}_{2} / \mathrm{SiO}_{2} @ \mathrm{Fe}_{3} \mathrm{O}_{4}$ photocatalyst was separated, dried at $70{ }^{\circ} \mathrm{C}$ to dry mass and calcined at $400{ }^{\circ} \mathrm{C}$ for $2 \mathrm{~h}$. 
In order to obtain metal modified $\mathrm{TiO}_{2}$ on $\mathrm{SiO}_{2} @ \mathrm{Fe}_{3} \mathrm{O}_{4}$ nanoparticles, $1.25 \mathrm{~cm}^{3}$ of $0.1 \mathrm{M}$ aqueous solution of particular metal precursor $(\mathrm{Cu}, \mathrm{Au}, \mathrm{Pt}$, and $\mathrm{Pd})$ was added dropwise into the suspension of $\mathrm{TiO}_{2} / \mathrm{SiO}_{2} @ \mathrm{Fe}_{3} \mathrm{O}_{4}$ photocatalyst and stirred for $30 \mathrm{~min}$. The amount of deposited metal on $\mathrm{TiO}_{2}$ was established to be $0.5 \mathrm{~mol} \%$ regarding the amount of $\mathrm{TiO}_{2}$. Metal ions were reduced by adding of $0.1 \mathrm{M}$ aqueous solution of sodium borohydride. The molar ratio of $\mathrm{NaBH}_{4}$ to metal ions equaled to 1.5. The obtained suspension of $\mathrm{Me}-\mathrm{TiO}_{2} / \mathrm{SiO}_{2} @ \mathrm{Fe}_{3} \mathrm{O}_{4}$ photocatalyst was centrifuged, dried at $70{ }^{\circ} \mathrm{C}$ to dry mass and calcined at $400{ }^{\circ} \mathrm{C}$ for $2 \mathrm{~h}$.

Preparation of samples of $\mathrm{Au}-\mathrm{TiO}_{2} @ \mathrm{SiO}_{2} / \mathrm{Fe}_{3} \mathrm{O}_{4}$ and $\mathrm{Cu}-\mathrm{TiO}_{2} @ \mathrm{SiO}_{2} / \mathrm{Fe}_{3} \mathrm{O}_{4}$ were repeated three times, and preparation of $\mathrm{Pt}-\mathrm{TiO}_{2} @ \mathrm{SiO}_{2} / \mathrm{Fe}_{3} \mathrm{O}_{4}$ was repeated two times without any changes in physicochemical properties (XRD, BET, colour) and photocatalytic activity.

\subsection{Measurements of Photocatalytic Activity}

Photocatalytic activities of the obtained samples were estimated by measurement of the rate of phenol decomposition in an aqueous solution under UV-vis irradiation. For each experiment, $50 \mathrm{mg}$ of the photocatalyst was suspended in $25 \mathrm{~cm}^{3}$ of aqueous solution of phenol $\left(\mathrm{Co} .=20 \mathrm{mg} \cdot \mathrm{dm}^{-3}\right)$. The obtained suspension was mixed in darkness for $30 \mathrm{~min}$ to provide uniform adsorption of phenol on photocatalyst surface, and then irradiated under continuously stirring using 300-W xenon lamp of $50-\mathrm{mW} \cdot \mathrm{cm}^{-2}$ power flux. Aliquots of $1.0 \mathrm{~cm}^{3}$ of the aqueous suspension were collected after equal time invertals of irradiation, and filtered through syringe filters $(\varphi=0.2 \mathrm{~m})$ to remove the photocatalyst particles. The temperature of the aqueous phase during irradiation was kept at $20{ }^{\circ} \mathrm{C}$ using a water bath. Phenol concentration was estimated by colorimetric method using a UV-vis spectrophotometer (Thermo Evolution 220). Phenol and phenol degradation intermediates were determined chromatographically using HPLC system (Kyoto, Japan) with UV-vis detector Shimadzu SPD-6A (detection wavelength: $254 \mathrm{~nm}$ ) (Kyoto, Japan) and a WAKOSIL-II 5C18 AR column (dimensions $4.6 \times 250 \mathrm{~mm}$ ) (Wako Pure Chemical Industries, Tokyo, Japan) with a mobile phase contained water, acetonitrile and phosphoric acid with volume ratio of 70:29.5:0.5, respectively. Photocatalytic degradation analysis were repeated at least three times for each obtained magnetic photocatalyst.

The effect of charge carrier scavengers was examined by addition into the phenol solution (before introduction of the photocatalyst) $1 \mathrm{~cm}^{3}$ of $500 \mathrm{mg} \cdot \mathrm{dm}^{-3}$ of tert-butyl alcohol (t-BuOH), ammonium oxalate $\left(\left(\mathrm{NH}_{4}\right)_{2} \mathrm{C}_{2} \mathrm{O}_{4}\right)$, silver nitrate $\left(\mathrm{AgNO}_{3}\right)$ or benzoquinone (BQ).

The formation of hydroxyl radicals in suspension of $\mathrm{Me}-\mathrm{TiO}_{2} / \mathrm{SiO}_{2} @ \mathrm{Fe}_{3} \mathrm{O}_{4}$ photocatalyst under UV-vis irradiation was evaluated by photoluminescence (PL) spectroscopy using terephthalic acid as a probe molecule under alkaline conditions. Hydroxyl radicals, produced during photocatalytic process, reactedwith terephtalic acid (TA) generating 2-hydroxyterephtalic acid, which emited fluorescence at around $426 \mathrm{~nm}$ [68]. Formation of hydroxyl radicals was estimated using the same experimental set-up as for measuring the decomposition rate of phenol under UV-vis light. After irradiation, the solution was filtered and analyzed on a Perkin Elmer LS55 (Waltham, MA, USA) fluorescence spectrophotometer with an excitation wavelength of $315 \mathrm{~nm}$ using NG3 and NG5 (Opole, Poland) cut-off filters. The spectra were recorded in the range of 360-550 nm.

\section{Conclusions}

The preparation procedure and characterization of new metal-modified $(\mathrm{Me}=\mathrm{Pd}, \mathrm{Au}, \mathrm{Pt}, \mathrm{Cu})$ $\mathrm{TiO}_{2} / \mathrm{SiO}_{2} @ \mathrm{Fe}_{3} \mathrm{O}_{4}$ nanocomposites was reported. XPS analysis revealed that the deposition of different metals changed the surface composition of photocatalysts. The highest content of oxygen vacancies $\left(\mathrm{Ti}^{3+}\right)$ was observed for $\mathrm{Pd}-\mathrm{TiO}_{2} / \mathrm{SiO}_{2} @ \mathrm{Fe}_{3} \mathrm{O}_{4}$ and $\mathrm{Cu}-\mathrm{TiO}_{2} / \mathrm{SiO}_{2} @ \mathrm{Fe}_{3} \mathrm{O}_{4}$ nanocomposites. For all obtained photocatalysts, the magnetic saturation was about $10-12 \mathrm{emu} \cdot \mathrm{g}^{-1}$ and did not depend on the amount and kind of metal deposited on the surface of $\mathrm{TiO}_{2}$. Mott-Schottky analysis showed a significant decrease in the slope of copper-modified $\mathrm{TiO}_{2}$ compared to that of $\mathrm{TiO}_{2}$, indicating an enhanced charge carrier density and faster charge transfer for $\mathrm{Cu}-$ modified $\mathrm{TiO}_{2}$ nanoparticles. 
The highest photooxidatation rate of phenol and mineralization, measured as TOC reduction, was observed for $\mathrm{Pd}-\mathrm{TiO}_{2} / \mathrm{SiO}_{2} @ \mathrm{Fe}_{3} \mathrm{O}_{4}$ and $\mathrm{Cu}-\mathrm{TiO}_{2} / \mathrm{SiO}_{2} @ \mathrm{Fe}_{3} \mathrm{O}_{4}$ photocatalysts. Based on fluorescence spectra and analysis of scavenger formation, it has been found that superoxide and hydroxyl radicals are main active species involved in the degradation, which attacks the phenyl ring yielding catechol, hydroquinone and benzoquinone generation, followed by oxalic acid and $\mathrm{CO}_{2}$ formation. It was found that the pathways for hydroquinone and catechol oxidation were different. Catechol was directly oxidized to oxalic acid and then mineralized to $\mathrm{CO}_{2}$, while the pathway of degradation for hydroquinone proceeded through the formation of a larger amount of intermediates, e.g., benzoquinone, maleic acid, which were further oxidized to aliphatic carboxylic acids and finally to $\mathrm{CO}_{2}$. The highest concentration of catechol and then oxalic acid during photocatalytic reaction was observed for the most active $\mathrm{Pd}-\mathrm{TiO}_{2} / \mathrm{SiO}_{2} @ \mathrm{Fe}_{3} \mathrm{O}_{4}$ and $\mathrm{Cu}-\mathrm{TiO}_{2} / \mathrm{SiO}_{2} @ \mathrm{Fe}_{3} \mathrm{O}_{4}$ photocatalysts. The enhanced activity was related to a decrease in noble metal and semi-noble metal particle size, an increase in the adsorption sites and efficient separation of charge carriers. For $\mathrm{Au}-\mathrm{TiO}_{2} / \mathrm{SiO}_{2} @ \mathrm{Fe}_{3} \mathrm{O}_{4}$ the keto-enol tautomeric equilibrium retarded the rate of phenol photomineralization. Therefore, it is proposed that the hydroquinone pathway is a limiting step for phenol degradation.

Acknowledgments: This research was financially supported by Polish NationalScience Centre (Grant No. NCN 2016/23/D/ST5/01021).

Author Contributions: Izabela Wysocka: performed magnetic photocatalysts synthesis, BET, TOC, ASA analysis and photocatalytic activity tests, Ewa Kowalska: supervised phenol degradation products analysis in cooperation with Izabela Wysocka, revised the manuscript, Konrad Trzciński: performed Mott-Schottky analysis, Marcin Łapiński: performed XPS analysis, Grzegorz Nowaczyk: performed STEM microscopy analysis, Anna Zielińska-Jurek: conceived the concept, designed the experiments, analyzed the data and wrote the manuscript.

Conflicts of Interest: The authors declare no conflict of interest.

\section{References}

1. Ohtani, B.; Prieto-Mahaney, O.O.; Li, D.; Abe, R. What is Degussa (Evonic) P25? Crystalline composition analysis, reconstruction from isolated pure particles and photocatalytic activity test. J. Photochem. Photobiol. A Chem. 2010, 216, 179-182. [CrossRef]

2. Wang, K.; Wei, Z.; Ohtani, B.; Kowalska, E. Interparticle electron transfer in methanol dehydrogenation on platinum- loaded titania particles prepared from P25. Catal. Today 2017. [CrossRef]

3. Bagheri, S.; Julkapli, N.M. Magnetite hybrid photocatalysis: Advance environmental remediation. Rev. Inorg. Chem. 2016, 36, 135-151. [CrossRef]

4. Beydoun, D.; Amal, R.; Low, G.K.-C.; McEvoy, S. Novel Photocatalyst:Titania-Coated Magnetite. Activity and Photodissolution. J. Phys. Chem. B 2000, 104, 4387-4396. [CrossRef]

5. Beydoun, D.; Amal, R.; Low, G.; McEvoy, S. Occurrence and prevention of photodissolution at the phase junction of magnetite and titanium dioxide. J. Mol. Catal. A Chem. 2002, 180, 193-200. [CrossRef]

6. Bagheri, S.; Julkapli, N.M. Modified iron oxide nanomaterials: Functionalization and application. J. Magn. Magn. Mater. 2016, 416, 117-133. [CrossRef]

7. Yu, X.; Liu, S.; Yu, J. Superparamagnetic $\gamma-\mathrm{Fe}_{2} \mathrm{O}_{3} @ \mathrm{SiO}_{2} @ \mathrm{TiO}_{2}$ composite microspheres with superior photocatalytic properties. Appl. Catal. B Environ. 2011, 104, 12-20. [CrossRef]

8. Liu, J.; Yang, S.; Wu, W.; Tian, Q.; Cui, S.; Dai, Z.; Ren, F.; Xiao, X.; Jiang, C. 3D Flowerlike $\alpha-\mathrm{Fe}_{2} \mathrm{O}_{3} @ \mathrm{TiO}_{2}$ Core-Shell Nanostructures: General Synthesis and Enhanced Photocatalytic Performance. ACS Sustain. Chem. Eng. 2015, 3, 2975-2984. [CrossRef]

9. Zielińska-Jurek, A.; Bielan, Z.; Dudziak, S.; Wolak, I.; Sobczak, Z.; Klimczuk, T.; Hupka, J. Design and Application of Magnetic Photocatalysts for Water Treatment. The Effect of Particle Charge on Surface Functionality. Catalysts 2017, 7. [CrossRef]

10. Jia, Y.; Liu, J.; Cha, S.; Choi, S.; Park, Y.C.; Liu, C. Magnetically separable Au- $\mathrm{TiO}_{2} /$ nanocube $\mathrm{ZnFe}_{2} \mathrm{O}_{4}$ composite for chlortetracycline removal in wastewater under visible light. J. Ind. Eng. Chem. 2017, 47, 303-314. [CrossRef] 
11. Laohhasurayotin, K.; Pookboonmee, S.; Viboonratanasri, D. Preparation of magnetic photocatalyst nanoparticles- $\mathrm{TiO}_{2} / \mathrm{SiO}_{2} / \mathrm{Mn}-\mathrm{Zn}$ ferrite-and its photocatalytic activity influenced by silica interlayer. Mater. Res. Bull. 2012, 47, 1500-1507. [CrossRef]

12. Chen, C.; Jaihindh, D.; Hu, S.; Fu, Y. Magnetic recyclable photocatalysts of Ni-Cu-Zn ferrite@SiO $\mathrm{STiO}_{2} @ \mathrm{Ag}$ and their photocatalytic activities. J. Photochem. Photobiol. A Chem. 2017, 334, 74-85. [CrossRef]

13. Vaiano, V.; Iervolino, G.; Sannino, D.; Murcia, J.J.; Hidalgo, M.C.; Ciambelli, P.; Navío, J.A. Photocatalytic removal of patent blue $\mathrm{V}$ dye on $\mathrm{Au}-\mathrm{TiO}_{2}$ and $\mathrm{Pt}-\mathrm{TiO}_{2}$ catalysts. Appl. Catal. B Environ. 2016, 188, 134-146. [CrossRef]

14. Hamzezadeh-Nakhjavani, S.; Tavakoli, O.; Akhlaghi, S.P.; Salehi, Z.; Esmailnejad-Ahranjani, P.; Arpanaei, A. Efficient photocatalytic degradation of organic pollutants by magnetically recoverable nitrogen-doped $\mathrm{TiO}_{2}$ nanocomposite photocatalysts under visible light irradiation. Environ. Sci. Pollut. Res. 2015, 22, 18859-18873. [CrossRef] [PubMed]

15. Long, N.Q.; Uyen, N.T.T.; Hoang, T.D.; Trung, D.B. Preparation, characterization and photocatalytic activity under visible light of magnetic $\mathrm{N}$-dopped $\mathrm{TiO}_{2}$. Int. J. Renew. Energy Environ. Eng. 2015, 3, $2-5$.

16. Larumbe, S.; Monge, M.; Gomez-Polo, C. Magnetically separable photocatalyst $\mathrm{Fe}_{3} \mathrm{O}_{4} / \mathrm{SiO}_{2} / \mathrm{N}-\mathrm{TiO}{ }_{2}$ hybrid nanostructure. IEEE Trans. Mag. 2014, 50, 6971-6975. [CrossRef]

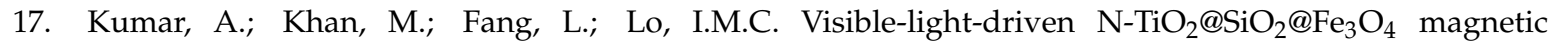
nanophotocatalysts: Synthesis, characterization, and photocatalytic degradation of PPCPs. J. Hazard. Mater. 2017, 1-9. [CrossRef]

18. Zielińska-Jurek, A. Progress, challenge, and perspective of bimetallic $\mathrm{TiO}_{2}$-based photocatalysts. J. Nanomater. 2015, 1-17. [CrossRef]

19. Choi, K.; Park, S.; Joo, B.; Jung, J. Recyclable Ag-coated $\mathrm{Fe}_{3} \mathrm{O}_{4} @ \mathrm{TiO}_{2}$ for efficient photocatalytic oxidation of chlorophenol. Surf. Coat. Technol. 2017, 320, 240-245. [CrossRef]

20. Khojasteh, H.; Salavati-Niasari, M.; Mazhari, M.-P.; Hamadanian, M. Preparation and characterization of $\mathrm{Fe}_{3} \mathrm{O}_{4} @ \mathrm{SiO}_{2} @ \mathrm{TiO}_{2} @ \mathrm{Pd}$ and $\mathrm{Fe}_{3} \mathrm{O}_{4} @ \mathrm{SiO}_{2} @ \mathrm{TiO}_{2} @ \mathrm{Pd}-\mathrm{Ag}$ nanocomposites and their utilization in enhanced degradation systems. RSC Adv. 2016, 6, 78043-78052. [CrossRef]

21. Li, X.; Liu, D.; Song, S.; Zhang, H. Fe $\mathrm{O}_{4} @ \mathrm{SiO}_{2} @ \mathrm{TiO} @ P t$ Hierarchical Core-Shell Microspheres: Controlled Synthesis, Enhanced Degradation System, and Rapid Magnetic Separation to Recycle. Cryst. Growth Des. 2014, 14, 5506-5511. [CrossRef]

22. Mohammadi-Aghdam, S.; Sarkhosh, B.; Tajoddin, N.N. Recyclable $\mathrm{Fe}_{3} \mathrm{O}_{4} / \mathrm{SiO}_{2} / \mathrm{TiO}_{2} / \mathrm{Cu}$ nanocomposites: Synthesis, characterization and investigation of the photocatalytic and magnetic property. J. Mater. Sci. Mater. Electron. 2017, 28, 9456-9463. [CrossRef]

23. Chun-Te Lin, J.; Sopajaree, K.; Jitjanesuwan, T.; Lu, M.-C. Application of visible light on copper-doped titanium dioxide catalyzing degradation of chlorophenols. Sep. Purif. Technol. 2017, 191, 233-243. [CrossRef]

24. Kim, S.; Hwang, S.; Choi, W. Visible Light Active Platinum-Ion-Doped $\mathrm{TiO}_{2}$ Photocatalyst. J. Phys. Chem. $B$ 2005, 109, 24260-24267. [CrossRef] [PubMed]

25. Colón, G.; Maicu, M.; Hidalgo, M.C.; Navío, J.A.; Kubacka, A.; Fernández-García, M. Gas phase photocatalytic oxidation of toluene using highly active Pt doped $\mathrm{TiO}_{2}$. J. Mol. Catal. A Chem. 2010, 320, 14-18. [CrossRef]

26. Zielińska-Jurek, A.; Zaleska, A. Ag/Pt-modified $\mathrm{TiO}_{2}$ nanoparticles for toluene photooxidation in the gas phase. Catal. Today 2014, 230, 104-111. [CrossRef]

27. Pham, T.; Lee, B.; Pham-Cong, D. Advanced removal of toluene in aerosol by adsorption and photocatalytic degradation of silver-doped $\mathrm{TiO}_{2} / \mathrm{PU}$ under visible light irradiation. RSC Adv. 2016, 6, 25346-25358. [CrossRef]

28. Yu, H.; Wang, X.; Sun, H.; Huo, M. Photocatalytic degradation of malathion in aqueous solution using an Au-Pd-TiO 2 nanotube film. J. Hazard. Mater. 2010, 184, 753-758. [CrossRef] [PubMed]

29. Grover, I.S.; Prajapat, R.C.; Singh, S.; Pal, B. Highly photoactive $\mathrm{Au}-\mathrm{TiO}_{2}$ nanowires for improved photo-degradation of propiconazole fungicide under UV/sunlight irradiation. Sol. Energy 2017, 144, 612-618. [CrossRef]

30. Pham, T.N.; Shi, D.; Resasco, D.E. Reaction kinetics and mechanism of ketonization of aliphatic carboxylic acids with different carbon chain lengths over $\mathrm{Ru} / \mathrm{TiO}_{2}$ catalyst. J. Catal. 3014, 334, 149-158. [CrossRef]

31. Giannakas, A.E.; Antonopoulou, M.; Papavasiliou, J.; Deligiannakis, Y.; Konstantinou, I. Photocatalytic performance of $\mathrm{Pt}-\mathrm{TiO}_{2}, \mathrm{Pt}-\mathrm{N}-\mathrm{TiO}_{2}$ and $\mathrm{Pt}-\mathrm{N} / \mathrm{F}-\mathrm{TiO}{ }_{2}$ towards simultaneous $\mathrm{Cr}(\mathrm{VI})$ reduction/benzoic acid oxidation: Insights into photogenerated charge carrier dynamics and catalyst properties. J. Photochem. Photobiol. A Chem. 2017, 349, 25-35. [CrossRef] 
32. Ding, Q.; Chen, S.; Shang, F.; Liang, J.; Liu, C. $\mathrm{Cu}_{2} \mathrm{O} / \mathrm{Ag}$ co-deposited $\mathrm{TiO}_{2}$ nanotube array film prepared by pulse-reversing voltage and photocatalytic properties. Nanotechnology 2016, 27, 485705. [CrossRef] [PubMed]

33. Yang, Z.; Lu, J.; Ye, W.; Yu, C.; Chang, Y. Preparation of $\mathrm{Pt} / \mathrm{TiO}_{2}$ hollow nanofibers with highly visible light photocatalytic activity. Appl. Surf. Sci. 2017, 392, 472-480. [CrossRef]

34. Theurich, J.; Lindner, M.; Bahnemann, D.W. Photocatalytic Degradation of 4-Chlorophenol in Aerated Aqueous Titanium Dioxide Suspensions: A Kinetic and Mechanistic Study. Langmuir 1996, 12, 6368-6376. [CrossRef]

35. Kim, S.; Choi, W. Visible-light-induced photocatalytic degradation of 4-chlorophenol and phenolic compounds in aqueous suspension of pure titania: Demonstrating the existence of a surface-complex-mediated path. J. Phys. Chem. B 2005, 109, 5143-5149. [CrossRef] [PubMed]

36. Montoya, J.F.; Ivanova, I.; Dillert, R.; Bahnemann, D.W.; Salvador, P.; Peral, J. Catalytic role of surface oxygens in $\mathrm{TiO}_{2}$ photooxidation reactions: Aqueous benzene photooxidation with $\mathrm{Ti}^{18} \mathrm{O}_{2}$ under anaerobic conditions. J. Phys. Chem. Lett. 2013, 4, 1415-1422. [CrossRef] [PubMed]

37. Su, R.; Tiruvalam, R.; He, Q.; Dimitratos, N.; Kesavan, L.; Hammond, C.; Lopez-Sanchez, J.A.; Bechstein, R.; Kiely, C.J.; Hutchings, G.J.; et al. Promotion of Phenol Photodecomposition over $\mathrm{TiO}_{2}$ Using $\mathrm{Au}$, Pd, and Au-Pd nanoparticles. ACS NANO 2012, 6, 6284-6292. [CrossRef] [PubMed]

38. Li, L.; Salvador, P.A.; Rohrer, G.S. Photocatalysts with internal electric fields. Nanoscale 2014, 6, $24-42$. [CrossRef] [PubMed]

39. Sobczyński, A.; Duczmal, L.; Zmudziński, W. Phenol destruction by photocatalysis on $\mathrm{TiO}_{2}$ : An attempt to solve the reaction mechanism. J. Mol. Catal. A Chem. 2004, 213, 225-230. [CrossRef]

40. Zhang, L.; Kanki, T.; Sano, N.; Toyoda, A. Pathways and kinetics on photocatalytic destruction of aqueous phenol. Environ. Monit. Assess. 2006, 115, 395-403. [CrossRef] [PubMed]

41. Diesen, V.; Jonsson, M. Comment on the use of phenols as probes for the kinetics of heterogeneous photocatalysis. Appl. Catal. B Environ. 2014, 158-159, 429-431. [CrossRef]

42. Hui, C.; Shen, C.; Tian, J.; Bao, L.; Ding, H.; Li, C.; Tian, Y.; Shi, X.; Gao, H.-J. Core-shell Fe $\mathrm{O}_{4} @ \mathrm{SiO}_{2}$ nanoparticles synthesized with well-dispersed hydrophilic $\mathrm{Fe}_{3} \mathrm{O}_{4}$ seeds. Nanoscale 2011, 3, 701-705. [CrossRef] [PubMed]

43. Belessi, V.; Lambropoulou, D.; Konstantinou, I.; Zboril, R.; Tucek, J.; Jancik, D.; Albanis, T.; Petridis, D. Structure and photocatalytic performance of magnetically separable titania photocatalysts for the degradation of propachlor. Appl. Catal. B Environ. 2009, 87, 181-189. [CrossRef]

44. Chi, Y.; Yuan, Q.; Li, Y.; Zhao, L.; Li, N.; Li, X.; Yan, W. Magnetically separable $\mathrm{Fe}_{3} \mathrm{O}_{4} @ \mathrm{SiO}_{2} @ \mathrm{TiO}_{2}-\mathrm{Ag}$ microspheres with well-designed nanostructure and enhanced photocatalytic activity. J. Hazard. Mater. 2013, 262, 404-411. [CrossRef] [PubMed]

45. Liu, H.; Jia, Z.; Ji, S.; Zheng, Y.; Li, M.; Yang, H. Synthesis of $\mathrm{TiO}_{2} / \mathrm{SiO}_{2} @ \mathrm{Fe}_{3} \mathrm{O}_{4}$ magnetic microspheres and their properties of photocatalytic degradation dyestuff. Catal. Today 2011, 175, 293-298. [CrossRef]

46. Xiong, L.; Li, J.; Yang, B.; Yu, Y. $\mathrm{Ti}^{3+}$ in the Surface of Titanium Dioxide: Generation, Properties and Photocatalytic Application. J. Nanomater. 2012, 2012, 1-13. [CrossRef]

47. Markowska-Szczupak, A.; Wang, K.; Rokicka, P.; Endo, M.; Wei, Z.; Ohtani, B.; Morawski, A.W.; Kowalska, E. The effect of anatase and rutile crystallites isolated from titania P25 photocatalyst on growth of selected mould fungi. J. Photochem. Photobiol. B Biol. 2015, 151, 54-62. [CrossRef] [PubMed]

48. Zielińska-Jurek, A.; Wei, Z.; Wysocka, I.; Szweda, P.; Kowalska, E. The effect of nanoparticles size on photocatalytic and antimicrobial properties of Ag-Pt/TiO 2 photocatalysts. Appl. Surf. Sci. 2015, 353, 317-325. [CrossRef]

49. Grabowska, E.; Zaleska, A.; Sorgues, S.; Kunst, M.; Etcheberry, A.; Colbeau-Justin, C.; Remita, H. Modification of titanium(IV) dioxide with small silver nanoparticles: Application in photocatalysis. J. Phys. Chem. C 2013, 117, 1955-1962. [CrossRef]

50. Kowalska, E.; Rau, S.; Ohtani, B. Plasmonic titania photocatalysts active under UV and visible-light irradiation: Influence of gold amount, size, and shape. J. Nanotechnol. 2012, 2012, 361853. [CrossRef]

51. Kowalska, E.; Mahaney, O.O.P.; Abe, R.; Ohtani, B. Visible-light-induced photocatalysis through surface plasmon excitation of gold on titania surfaces. Phys. Chem. Chem. Phys. 2010, 12, 2344. [CrossRef] [PubMed]

52. Zielińska, A.; Skwarek, E.; Zaleska, A.; Gazda, M.; Hupka, J. Preparation of silver nanoparticles with controlled particle size. Procedia Chem. 2009, 1, 1560-1566. [CrossRef] 
53. Radecka, M.; Rekas, M.; Trenczek-Zajac, A.; Zakrzewska, K. Importance of the band gap energy and flat band potential for application of modified $\mathrm{TiO} 2$ photoanodes in water photolysis. J. Power Sources 2008, 181, 46-55. [CrossRef]

54. Tanabe, I.; Ozaki, Y. Consistent changes in electronic states and photocatalytic activities of metal (Au, Pd, $\mathrm{Pt}$ )-modified $\mathrm{TiO}_{2}$ studied by far-ultraviolet spectroscopy. Chem. Commun. 2014, 1, 2117-2119. [CrossRef] [PubMed]

55. Subramanian, V.; Wolf, E.; Kamat, P.V. Semiconductor-Metal Composite Nanostructures. To What Extent Do Metal Nanoparticles Improve the Photocatalytic Activity of $\mathrm{TiO}_{2}$ Films? J. Phys. Chem. B 2001, 105, 11439-11446. [CrossRef]

56. Rashid, J.; Barakat, M.A.; Ruzmanova, Y.; Chianese, A. $\mathrm{Fe}_{3} \mathrm{O}_{4} / \mathrm{SiO}_{2} / \mathrm{TiO}_{2}$ nanoparticles for photocatalytic degradation of 2-chlorophenol in simulated wastewater. Environ. Sci. Pollut. Res. 2015, 22, 3149-3157. [CrossRef] [PubMed]

57. Lv, K.; Guo, X.; Wu, X.; Li, Q.; Ho, W.; Li, M.; Ye, H.; Du, D. Photocatalytic selective oxidation of phenol to produce dihydroxybenzenes in a $\mathrm{TiO}_{2} / \mathrm{UV}$ system: Hydroxyl radical versus hole. Appl. Catal. B Environ. 2016, 199, 405-411. [CrossRef]

58. Zielińska-Jurek, A.; Kowalska, E.; Sobczak, J.W.; Lisowski, W.; Ohtani, B.; Zaleska, A. Preparation and characterization of monometallic $(\mathrm{Au})$ and bimetallic $(\mathrm{Ag} / \mathrm{Au})$ modified-titania photocatalysts activated by visible light. Appl. Catal. B Environ. 2011, 101, 504-514. [CrossRef]

59. Kowalska, E.; Janczarek, M.; Rosa, L.; Juodkazis, S.; Ohtani, B. Mono- and bi-metallic plasmonic photocatalysts for degradation of organic compounds under UV and visible light irradiation. Catal. Today 2014, 230, 131-137. [CrossRef]

60. Kalan, R.E.; Yaparatne, S.; Amirbahman, A.; Tripp, C.P. P25 titanium dioxide coated magnetic particles: Preparation, characterization and photocatalytic activity. Appl. Catal. B Environ. 2016, 187, 249-258. [CrossRef]

61. Emeline, A.V.; Zhang, X.; Murakami, T.; Fujishima, A. Activity and selectivity of photocatalysts in photodegradation of phenols. J. Hazard. Mater. 2012, 121-212, 54-160. [CrossRef] [PubMed]

62. Azevedo, E.B.; Aquino Neto, F.R.; Dezotti, M. $\mathrm{TiO}_{2}$-Photocatalyzed degradation of phenol in saline media in an annular reactor: Hydrodynamics, lumped kinetics, intermediates, and acute toxicity. Braz. J. Chem. Eng. 2009, 26, 75-87. [CrossRef]

63. Montoya, J.F.; Velásquez, J.A.; Salvador, P. The direct-indirect kinetic model in photocatalysis: A reanalysis of phenol and formic acid degradation rate dependence on photon flow and concentration in $\mathrm{TiO}_{2}$ aqueous dispersions. Appl. Catal. B Environ. 2009, 88, 50-58. [CrossRef]

64. Miyazaki, T.; Katsumura, Y.; Lin, M.; Muroya, Y.; Kudo, H.; Taguchi, M.; Asano, M.; Yoshida, M. Radiolysis of phenol in aqueous solution at elevated temperatures. Radiat. Phys. Chem. 2006, 75, 408-415. [CrossRef]

65. Murcia, J.J.; Hidalgo, M.C.; Navío, J.A.; Araña, J.; Doña-Rodríguez, J.M. Correlation study between photo-degradation and surface adsorption properties of phenol and methyl orange on $\mathrm{TiO}_{2} \mathrm{Vs}$ platinum-supported $\mathrm{TiO}_{2}$. Appl. Catal. B Environ. 2014, 150-151, 107-115. [CrossRef]

66. Wei, Z.; Rosa, L.; Wang, K.; Endo, M.; Juodkazis, S.; Ohtani, B.; Kowalska, E. Size-controlled gold nanoparticles on octahedral anatase particles as efficient plasmonic photocatalyst. Appl. Catal. B Environ. 2017, 206, 393-405. [CrossRef] [PubMed]

67. Santos, A.; Yustos, P.; Quintanilla, A.; Rodríguez, S.; García-Ochoa, F. Route of the catalytic oxidation of phenol in aqueous phase. Appl. Catal. B Environ. 2002, 39, 97-113. [CrossRef]

68. Ishibashi, K.I.; Fujishima, A.; Watanabe, T.; Hashimoto, K. Detection of active oxidative species in $\mathrm{TiO}_{2}$ photocatalysis using the fluorescence technique. Electrochem. Commun. 2000, 2, 207-210. [CrossRef]

(C) 2018 by the authors. Licensee MDPI, Basel, Switzerland. This article is an open access article distributed under the terms and conditions of the Creative Commons Attribution (CC BY) license (http:/ / creativecommons.org/licenses/by/4.0/). 